\title{
Efeitos potenciais da política tributária sobre o consumo de alimentos e insumos agropecuários: uma análise de equilíbrio geral inter-regional
}

\author{
Cárliton Vieira dos Santos* \\ Joaquim Bento de Souza Ferreira Filho**
}

Resumo: Este trabalho analisa os efeitos potenciais de longo prazo sobre a economia brasileira de duas políticas no campo da tributação indireta: a) a redução dos tributos sobre o consumo de alimentos pelas famílias e; b) a redução dos tributos sobre os principais insumos utilizados pela agropecuária. A análise é implementada através de dois exercícios de simulação com o uso de um modelo aplicado de equilíbrio geral interregional calibrado para o ano de 2001. Os resultados de ambas as simulações mostram-se semelhantes, exceto em termos de magnitude: os efeitos mais intensos estão associados à política de redução da tributação sobre alimentos. Ambas as simulações mostram expansão no nível de atividade econômica nas regiões mais pobres do País e retração nas mais ricas. Elas mostram também um potencial de melhorar o bemestar das classes de menor renda em todas as regiões, especialmente nas mais pobres: Norte e Nordeste. O impacto negativo sobre a arrecadação revela-se como a principal restrição à implementação dessas políticas. Constata-se que os efeitos das políticas tributárias diferem regionalmente, muitas vezes de maneira substancial, o que reforça a utilidade dos

* Prof. Adjunto do Curso de Ciências Econômicas da UNIOESTE - Campus de Cascavel. Pesquisador do Grupo de Pesquisa em Economia Aplicada (GPEA). carlitonsantos@ uol.com.br

**Prof. Titular do Departamento de Economia, Administração e Sociologia da Esalq/ USP. jbsferre@esalq.usp.br 
modelos aplicados de equilíbrio geral inter-regionais na geração de informações que possam subsidiar a formulação de políticas no Brasil.

Palavras-chave: política tributária, tributos indiretos, alimentos, agropecuária, equilíbrio geral.

Classificação JEL: R13, H20

Abstract: This paper analyses the potentials long run effects on the Brazilian economy of two policies in the field of the indirect taxes: a) the reduction of indirect taxes on food consumption by the households and; b) the reduction of indirect taxes on the main inputs used in the agricultural activity. The analysis is accomplished through two simulation exercises using a static inter-regional applied general equilibrium model. The benchmark year is 2001. The results of both simulations are found to be similar, except in terms of magnitude: the most intense effects are associated to the reduction the taxation on foods. Both simulations show expansion in the level of economic activity in the poorest regions of the country and reduction in the richest. They also show a potential for improving the welfare of the low income classes in all regions, especially in the poorest: North and Northeast. The negative impact on the governments' revenue is the main restriction to the implementation of these policies. Results also show that the effects of tax policies differ among regions, sometimes substantially, what strengthen the usefulness the interregional applied general equilibrium models for the analysis of tax policies impacts in Brazil.

Key words: tax policy, indirect taxes, foods, agricultural activity, general equilibrium.

JEL Classification: R13, H20

\section{Introdução}

O Brasil, além de possuir uma carga tributária elevada relativamente a outros países de grau similar de desenvolvimento, possui um sistema

RER, Rio de Janeiro, vol. 45, no 04, p. 921-962, out/dez 2007 - Impressa em novembro 2007 
tributário complexo, que instiga a competição tributária e é socialmente injusto, ou seja, onera relativamente mais as famílias mais pobres do que as mais ricas. Diagnósticos como estes têm alimentado o debate em torno da reforma tributária ao longo dos últimos doze anos. Tem havido também um consenso de que o grande desafio da reforma encontra-se no sistema de tributação indireta, dotado das maiores deficiências e considerado inequivocamente regressivo.

A regressividade do sistema de tributação indireta no Brasil deve-se, em parte, à expressiva carga de tributos que recai sobre os alimentos, que é agravada pela significativa participação dessa categoria de despesas no orçamento das famílias mais pobres. Estimativas de Magalhães et al. (2001) mostram que a carga tributária sobre alimentos encontrava-se na faixa de $14,1 \%$, na média, para as grandes regiões urbanas pesquisadas pela Pesquisa de Orçamentos Familiares do Instituto Brasileiro de Geografia e Estatística (POF/IBGE) de 1995-96. A participação dos gastos com alimentação no rendimento familiar per capita das famílias mais pobres, por sua vez, situava-se acima dos 50\%, na média, segundo dados da mesma POF.

Neste contexto, pode-se argumentar que políticas públicas redutoras dos preços dos alimentos no Brasil tendem a apresentar grande potencial de melhoria do bem-estar das populações mais pobres. A redução da carga tributária sobre produtos alimentares e sobre os insumos empregados no setor agropecuário são exemplos de instrumentos de política que podem ser utilizados para se atingir esse fim. O argumento central é que medidas dessa natureza contribuem para a redução dos preços dos alimentos, e como esse tipo de despesa absorve parcela expressiva dos orçamentos da população de mais baixa renda, essa parcela da sociedade tende a ser mais beneficiada relativamente à de maior renda.

Alguns estudos empíricos para a economia brasileira, sob a abordagem de equilíbrio parcial, corroboram o argumento acima ${ }^{1}$. É possível, no entanto, que existam outros efeitos diretos e indiretos dessas políticas que não são capitados por análises de equilíbrio parcial. Em particular, não são claros, a priori, os efeitos potenciais dessas políticas sobre o nível de atividade econômica agregada e setorial, sobre o

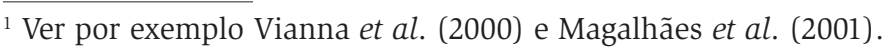


emprego e sobre a arrecadação tributária. Do mesmo modo, não são claros os efeitos que as políticas tributárias de âmbito nacional podem ter sobre as economias regionais. Os estudos empíricos sobre tributação no Brasil raramente têm retratado este último aspecto e, quando são considerados, a ausência de instrumentais formais de análise tem limitado a produção de informações suficientemente consistentes para subsidiar a formulação de políticas. Avaliações mais completas sobre o tema requerem análises que superem a intuição econômica ou o uso de modelos de equilíbrio parcial. A alternativa metodológica apropriada nesses casos é a utilização de modelos inter-regionais de equilíbrio geral aplicados.

Nesse sentido, no momento em que ainda se discute a reforma tributária no Brasil, procura-se, neste artigo, analisar, por meio de um modelo aplicado de equilíbrio geral inter-regional, os efeitos potenciais sobre economia brasileira, em nível nacional e regional, de duas políticas nesse campo da tributação, a saber: 1) a redução das alíquotas de tributos indiretos sobre os principais alimentos consumidos pelas famílias e; 2) a redução das alíquotas de tributos indiretos sobre os principais insumos empregados na atividade agropecuária.

\section{Metodologia}

O instrumental analítico utilizado neste trabalho é um modelo interregional de equilíbrio geral aplicado denominado The Enormous Regional Model for BRazilian economy (TERM-BR). Esse modelo é baseado no The Enormous Regional Model (TERM) construído para a economia australiana $^{2}$. O ano de referência para a análise é 2001, por ser o mais recente para o qual se dispunha de um maior conjunto de dados necessários a um estudo dessa natureza no momento da sua definição.

O TERM-BR segue a tradição australiana de modelagem de equilíbrio geral, ou seja, é um modelo do tipo Johansen, cuja estrutura matemática é representada por um conjunto de equações, na sua grande maioria não-lineares, porém, descritas na forma linearizada, e cuja solução é dada em taxa de crescimento (variação percentual). O modelo é estático, portanto, apropriado para análises do tipo estático-comparativas.

${ }^{2}$ Para maiores detalhes sobre o TERM, consultar Horridge et al. (2005). 
Para a construção do banco de dados e implementação do modelo foi utilizado o software GEMPACK ${ }^{3}$.

O TERM-BR é um modelo do tipo bottom-up ${ }^{4}$ apropriado para lidar, ao mesmo tempo, com dados regionais e setoriais altamente desagregados, permitindo que sejam geradas soluções com muito mais rapidez do que qualquer outro modelo bottom-up até então utilizado em estudos empíricos para o Brasil. Devido à grande extensão territorial brasileira, sua heterogeneidade regional e sua diversidade setorial, essa característica do TERM-BR faz dele um instrumento bastante útil para análise de impactos de políticas.

A especificação utilizada na implementação do TERM-BR permite distinguir 27 regiões (26 estados e o Distrito Federal) ${ }^{5}$; 42 setores produtivos (os da matriz insumo-produto brasileira e do Sistema de Contas Nacionais) e 52 produtos (Agropecuária produz 11 produtos e os demais setores produzem um único produto); 2 tipos de serviços de margem (de comércio e de transporte); 3 fatores de produção (trabalho, capital e terra, este último de uso exclusivo da Agropecuária); 10 tipos de ocupação, distingüidos conforme as classes de salários da Pesquisa de Orçamentos Familiares (POF); e 4 demandantes finais (famílias, governo, exportação e investimento).

\subsection{A estrutura de produção no TERM-BR}

A estrutura de produção no TERM-BR é organizada hierarquicamente em três níveis. Esses níveis representam as etapas de otimização no processo produtivo das firmas. O primeiro nível (no topo da estrutura)

\footnotetext{
${ }^{3}$ A documentação completa sobre o GEMPACK está disponível para download no endereço eletrônico: http://www.monash.edu.au/policy/gpdoc.htm.

${ }^{4}$ Modelos do tipo bottom-up tratam cada uma das regiões especificadas como se fosse uma economia separada, ou seja, é como se existisse um modelo completo para cada região, porém, havendo uma interação entre elas e entre os agentes regionais e nacionais. Os resultados nacionais neste tipo de modelo são obtidos a partir da agregação ponderada dos resultados regionais. Isso difere dos modelos do tipo top-down, onde o resultado nacional é obtido primeiro e os regionais são obtidos com base em participações no total nacional.

${ }^{5}$ No entanto, para facilitar a exposição, a maioria dos resultados apresentados neste artigo foram agregados para o nível de 6 grandes regiões: Norte, Nordeste, São Paulo, Resto do Sudeste, Sul e Centro-Oeste.
}

RER, Rio de Janeiro, vol. 45, no 04, p. 921-962, out/dez 2007 - Impressa em novembro 2007 
indica que a produção dos diversos bens e serviços provém de uma função Constant Elasticity of Transformation (CET). O segundo nível indica que bens intermediários (insumos) compostos, formados a partir das origens doméstica e importada, são combinados com fatores primários compostos e tributos sobre a produção usando uma função de produção Leontief. O terceiro nível mostra que o bem intermediário composto é produzido através da combinação entre o bem doméstico e importado, enquanto o fator primário composto é produzido utilizando uma função Constant Elasticity of Substitution (CES) que agrega terra, trabalho e capital. As importações se originam de um único mercado externo, representado pelo Resto do Mundo. A utilização de funções CES nesse nível da estrutura de produção implica a adoção da hipótese de Armington na diferenciação de produtos quanto à origem. De acordo com essa hipótese, bens de diferentes origens (doméstica ou importada) são tratados como substitutos imperfeitos. No último nível da estrutura de produção (na base), o fator trabalho é definido como um composto de diferentes tipos de ocupação, agregados por uma CES. Nesse nível, há ainda a possibilidade de substituição imperfeita entre as origens regionais do insumo intermediário doméstico, determinada por uma função CES.

\subsection{A estrutura de demanda no TERM-BR}

A estrutura de demanda no TERM-BR é também organizada hierarquicamente, porém em quatro níveis. Esta estrutura descreve o mecanismo de origem dos fluxos de bens e serviços para o atendimento das demandas de todos os usuários representados no modelo. No primeiro nível (topo), os usuários finais fazem a escolha entre bens de origem doméstica e importada, com base em uma função CES. No segundo nível, é determinado como a demanda por cada bem (doméstico ou importado) é atendida pelas diversas regiões de origem. Nesse nível, uma função CES é empregada para determinar a escolha das regiões fornecedoras (regiões de origem). No terceiro nível da estrutura de demanda, é mostrado como os valores dos fluxos de cada bem, sem os tributos, resultam dos somatórios dos valores a preços básicos e dos valores de margens de comércio e transporte associados a cada um desses fluxos. O quarto e último nível (base) da estrutura de demanda, mostra o mecanismo que 
determina a origem das margens necessárias para transferir cada bem das regiões de origem para cada região de uso (destino). Uma função CES é utilizada neste último nível para direcionar esta decisão.

A demanda das famílias, em particular, no TERM-BR, obedece a um sistema linear de dispêndio. Elas determinam a composição ótima de suas cestas de consumo escolhendo produtos que maximizam uma função utilidade do tipo Klein-Rubin - também conhecida como StoneGeary - sujeitas a uma restrição orçamentária. A partir da maximização desta função utilidade é gerado um sistema de equações de demanda denominado sistema linear de dispêndio no qual a despesa com cada bem é descrito como uma função linear do dispêndio total e dos preços de todos os bens. Por construção, as equações que compõem esse sistema são homogêneas de grau zero em preços e renda.

As exportações de cada região para o Resto do Mundo defrontam-se com uma demanda de elasticidade constante. A demanda por investimento e a demanda do governo são tratadas no modelo como exógenas.

\subsection{A tributação indireta no TERM-BR}

O TERM-BR trata os tributos indiretos como ad valorem, cujas alíquotas incidem sobre os fluxos de bens e serviços mensurados a preços básicos. Esses tributos indiretos são tratados no modelo em dois blocos distintos: os tributos sobre produtos (envolvendo especialmente ICMS, IPI, ISS, IOF, dentre outros) e os tributos sobre a produção (COFINS, PIS/PASEP, Contribuição do salário educação, Contribuição ao sistema "S", etc).

As simulações implementadas neste trabalho retratam apenas mudanças nas alíquotas dos tributos pertencentes ao primeiro bloco: dos tributos indiretos sobre produtos. A principal justificativa para isso advém da representatividade dos tributos sobre produtos no sistema tributário brasileiro: apenas dois tributos desse bloco, o ICMS e o IPI, responderam juntos por $28,26 \%$ de toda arrecadação tributária brasileira em 2001. Já os tributos sobre a produção responderam, em conjunto, por $18,38 \%$ do total arrecadado aos cofres públicos naquele ano.

A grande vantagem do TERM-BR em relação aos modelos de equilíbrio parcial para análise de impactos de mudanças na tributação indireta é permitir que a base tributária possa variar endogenamente em 
resposta à mudança na alíquota tributária. Como conseqüência, ao se proceder a simulação de uma mudança na alíquota de algum tributo indireto sobre produto o modelo capta a variação total na receita do governo oriunda de dois tipos de efeito: os de primeira ordem, associados exclusivamente à mudança na alíquota, mantendo a base tributária inicial e; os de segunda ordem, associados à mudança na própria base tributária em resposta à mudança na alíquota. Assim, a estimação do impacto sobre a receita dos governos diante de uma alteração na alíquota de tributos indiretos sobre produtos pode ser representada da seguinte forma: ${ }^{6}$

$$
V T A X=V B A S \times t
$$

então

$$
\Delta V T A X=\underbrace{V B A S \times \Delta t}_{\text {efeitos de primeira ordem }},+\underbrace{\Delta V B A S \times t}_{\text {efeitos de segunda ordem }}
$$

sendo: VTAX a receita com tributos indiretos sobre produtos; VBAS a base tributária e; $t$ a alíquota tributária, que empiricamente corresponde à alíquota efetiva do tributo.

As equações (1) e (2), além de importantes na estimação do impacto de mudanças nas alíquotas dos tributos indiretos sobre a receita dos governos, são necessárias também para atualizar as diversas matrizes de dados de tributos sobre produtos no banco de dados do modelo. Essas atualizações, por sua vez, são responsáveis por transmitir os impactos da política tributária a todo o sistema econômico.

Outra característica importante do TERM-BR é não exigir que sejam estabelecidas previamente hipóteses sobre o grau de repasse, de produtores para consumidores, das mudanças na tributação indireta. Isto difere dos modelos de equilíbrio parcial, que geralmente adotam hipóteses de repasse, total ou parcial, das mudanças na tributação indireta dos produtores para os consumidores intermediários ou finais. $\mathrm{Na}$

\footnotetext{
${ }^{6}$ Esta formulação está representada também em Domingues e Haddad (2003), que, por sua vez, é equivalente à formulação representada pela equação (31) apresentada em Horridge (2001, p. 37), ao descrever o modelo ORANI-G, uma versão genérica do modelo ORANI.
} 
análise empreendida neste trabalho o grau de repasse é determinado endogenamente: as reduções nas alíquotas efetivas dos tributos indiretos nas simulações implementadas afetam preços e quantidades de equilíbrio, que, por sua vez, sinalizam a extensão dos repasses. Portanto, no TERM-BR, o grau de repasse dos produtores aos consumidores da política de redução de tributos depende dos parâmetros que caracterizam a estrutura de mercado, o grau de concorrência externa, a oferta e a demanda domésticas.

Mais detalhes sobre a estrutura teórica e do banco de dados do TERM-BR, além da formulação matemática no formato utilizado no GEMPACK, podem ser encontrados em Santos (2006).

\subsection{O banco de dados do modelo}

O banco de dados do TERM-BR é composto basicamente por: a) uma matriz insumo-produto inter-regional para o Brasil, referente ao ano de 2001, estimada pelos autores; b) uma matriz de comércio, para o ano de 2001, também estimada pelos autores, representando os fluxos de bens e serviços de cada região de origem (r) para cada região de destino (d); c) uma série de coeficientes estruturais e parâmetros comportamentais.

O processo de construção do banco de dados insumo-produto do TERM-BR teve início com a estimação de uma matriz insumo-produto nacional a preços básicos para o Brasil, para o ano de 2001. A estimação foi feita a partir dos dados das tabelas de Recursos e Usos de Bens e Serviços do Sistema de Contas Nacionais do Brasil referentes ao ano de 2001 (IBGE, 2003b), e da matriz insumo-produto brasileira de 1996 (IBGE, 1999). Optou-se pela estimação porque a última matriz insumoproduto oficial disponível para o País refere-se ao distante ano de 1996.

A matriz insumo-produto inter-regional para 2001 foi obtida da regionalização dos dados da matriz insumo-produto nacional a preços básicos estimada. Para isso, foram requeridos dados regionais envolvendo basicamente a distribuição da produção setorial e dos agregados de demanda final entre as regiões especificadas no modelo. Os dados utilizados para a distribuição da produção agropecuária foram obtidos do Sistema IBGE de Recuperação Automática (SIDRA), referentes ao ano 
de 2001 - IBGE (2005). Para os demais setores foram utilizados como proxy da produção regional os dados de salários regionais oriundos do Cadastro Central de Empresas para o ano de 2001 (IBGE, 2003a).

Dados sobre a população regional em 2001, também necessários à implementação do modelo, foram obtidos das Contas Regionais do Brasil - 2002 (IBGE, 2004a). Os dados sobre tributos indiretos foram obtidos do Sistema de Contas Nacionais e de publicação específica do IBGE sobre finanças públicas, intitulada Finanças Públicas do Brasil (IBGE, 2004b).

Uma matriz de comércio, representando os fluxos de bens e serviços de cada região de origem (r) para cada região de destino (d), foi estimada com base em um modelo gravitacional, utilizando as informações sobre produção e demanda regional de cada produto e uma matriz de distâncias físicas, em quilômetros, entre as capitais das 27 regiões (estados) especificadas no TERM-BR. O método RAS foi utilizado para obter a consistência necessária entre as estimativas iniciais dos fluxos de comércio (origem-destino) e os totais de produção e demanda de cada produto em cada região.?

A grande maioria dos coeficientes e parâmetros necessários à implementação do modelo foi obtida do processo de calibração. O restante foi obtido da literatura econométrica ou - nos casos de ausência de estimativas específicas para o Brasil - de outros modelos aplicados de equilíbrio geral. Os valores assumidos para as elasticidades de transformação foram idênticos para todos os setores, seguindo procedimento padrão adotado nos modelos australianos nos casos de ausência de estimativas específicas. As elasticidades de Armington para bens intermediários para 28 setores foram obtidos de Tourinho et al. (2003); para os outros 14 setores os valores foram extraídos do banco de dados do modelo GTAP (Global Trade Analysis Project) ${ }^{8}$. As elasticidades de substituição

\footnotetext{
${ }^{7}$ Esse método é bastante empregado em Economia no contexto dos modelos de insumoproduto e matrizes de Contabilidade Social, sendo passível também de aplicações em outras circunstâncias. Um exemplo simples do funcionamento do método pode ser visto em Fochezatto e Carvalho (2002). Para maiores detalhes sobre o método sugere-se consultar Miller e Blair (1985).

${ }^{8}$ O GTAP é um modelo estático de equilíbrio geral aplicado projetado para análises relativas ao comércio internacional, desenvolvido por um consórcio que leva o mesmo nome (Hertel, 1997).
} 
entre origens domésticas foram também obtidas do banco de dados do GTAP. As elasticidades de substituição entre origens de margens são provenientes do modelo EMERALD ${ }^{9}$, assim como as elasticidades de substituição entre fatores primários e as elasticidades de substituição entre tipos de ocupação. O baixo valor adotado para a elasticidade de substituição $(0,20)$ implica que há um baixo grau de substituição entre os diversos tipos de trabalho (diferentes tipos de ocupação). Para a elasticidade da demanda de exportação de cada região para o Resto do Mundo, adotou-se um mesmo valor para todos os setores. As elasticidades de dispêndio, associadas à demanda das famílias, são obtidas do banco de dados do GTAP e de estimativas de Hoffmann (2000).

Os efeitos sobre o bem-estar são analisados com base em índices de preços ao consumidor por classe de renda e região. O índice utilizado é o Laspeyres, que é uma relação entre o custo de aquisição de uma determinada cesta de mercadorias no período $t$ e o custo de aquisição desta mesma cesta no período-base, sendo a cesta de mercadorias definida no período-base. As dez classes de renda estabelecidas, de maneira semelhante a Ferreira Filho e Horridge (2004), foram baseadas na POF, de tal forma que POF[1] representa a classe de menor renda e POF[10] a classe de maior renda. ${ }^{10}$ Os índices de preços ao consumidor, por classe de renda e por região, foram calculados tendo como fator de ponderação as parcelas de cada bem no consumo por classe de renda e região. Os dados para determinação destas parcelas são oriundos da POF 1995-1996 (IBGE, 1998).

\subsection{O fechamento macroeconômico utilizado}

Utilizou-se um fechamento macroeconômico de longo prazo em todas as simulações. Esta opção se justifica, em primeiro lugar, porque os efeitos das políticas tributárias sobre a configuração da economia

${ }^{9}$ O EMERALD é um modelo aplicado de equilíbrio geral para a Indonésia, e é também derivado do TERM; sobre esse modelo, ver Pambudi (2005).

${ }^{10}$ POF[1] de 0 a 2 salários mínimos; POF[2] de mais de 2 a 3 salários mínimos; POF[3] de mais de 3 a 5 salários mínimos; POF[4] mais de 5 a 6 salários mínimos; POF[5] de mais de 6 a 8 salários mínimos; POF[6] de mais de 8 a 10 salários mínimos; POF[7] de mais de 10 a 15 salários mínimos; POF[8] de mais de 15 a 20 salários mínimos; POF[9] de mais de 20 a 30 salários mínimos e, finalmente, POF[10] acima de 30 salários mínimos.

RER, Rio de Janeiro, vol. 45, no 04, p. 921-962, out/dez 2007 - Impressa em novembro 2007 
geralmente se verificam após um prazo relativamente longo de tempo. No curto prazo, conforme argumentam Kehoe et al. (1988), os efeitos de tais políticas não raramente são opostos aos esperados.

As principais características do fechamento utilizado podem ser assim descritas:

- Os estoques de capital em cada indústria e região são determinados endogenamente; eles podem se deslocar intersetorial e interregionalmente, esse movimento se dá em direção às regiões mais atrativas. As taxas de retorno do capital em cada indústria e região, por outro lado, são consideradas fixas (exógenas).

- O investimento setorial pode variar no longo prazo, isto é, as firmas, no longo prazo, podem reavaliar decisões de investimento. A regra de comportamento adotada aqui é que investimento acompanha o estoque de capital.

- A população e a oferta de trabalho agregada (nível de emprego agregado) são fixas, isto é, exógenas ao modelo. O salário real, por outro lado, é determinado endogenamente.

- A oferta de trabalho (nível de emprego) pode se deslocar intersetorial e inter-regionalmente, isto é, diferentemente do comportamento agregado (nacional), a distribuição setorial e espacial da força de trabalho é determinada endogenamente. Dentro de cada região o trabalho é completamente móvel entre os setores, enquanto entre as regiões a mobilidade é determinada pelo diferencial de salários entre elas.

- O consumo do governo foi mantido fixo em ambos os níveis, nacional e regional. Esta simplificação foi utilizada, dentre outros motivos, para se limitar o foco de análise.

- O consumo real das famílias é endógeno, em nível nacional e regional.

- A razão Balança Comercial/PIB é tratada como exógena, assim, o consumo real das famílias e o investimento, que são os únicos componentes endógenos da absorção doméstica, ajustam-se para satisfazer as restrições da balança comercial. Esta é uma visão consistente com o fato de que eventuais déficits comerciais não podem ser financiados indefinidamente pelo exterior.

- As variáveis de choque tecnológico também são exógenas, uma 
vez que o modelo não apresenta nenhuma teoria subjacente de crescimento endógeno.

- Finalmente, o numéraire do modelo é o índice de preços ao consumidor agregado (nacional), enquanto a taxa de câmbio nominal é endógena.

Com esse fechamento, o TERM-BR fica sendo composto por 168.603 variáveis endógenas (e de equações) e 75.451 variáveis exógenas.

\subsection{As simulações}

Neste artigo são analisadas duas simulações de política tributária implementadas com o TERM-BR: 1) redução pela metade das alíquotas efetivas dos tributos indiretos sobre os principais produtos alimentícios consumidos pelas famílias (Experimento 1);2) redução pela metade das alíquotas efetivas dos tributos indiretos sobre os principais insumos utilizados pela Agropecuária (Experimento 2).

O procedimento para a implementação do primeiro experimento consistiu, inicialmente, da identificação dos principais produtos alimentícios consumidos pelas famílias, dentre o conjunto de 52 produtos especificados no TERM-BR. Isso foi feito calculando-se as participações de cada produto no consumo total das famílias, a preços básicos; estas informações foram extraídas das etapas intermediárias de preparação do banco de dados do modelo. Os produtos selecionados foram os cinco seguintes: Outros Produtos Agropecuários, Outros Produtos Alimentares, Abate de Animais, Beneficiamento de Produtos Vegetais e Indústria de Laticínios.

As alíquotas efetivas $(t)$ para cada um desses cinco produtos foram calculadas como a razão entre o total dos gastos das famílias com os tributos indiretos sobre tais produtos e os correspondentes valores desses produtos mensurados a preços básicos - isto é, sem os encargos tributários e sem as margens. É importante notar que as alíquotas efetivas, diferentemente do que ocorre com as nominais, levam em conta a evasão fiscal, pois são calculadas a partir de dados sobre o montante de tributos efetivamente recolhidos. Os valores utilizados para choque no Experimento 1, para os cinco produtos alvo da política, encontram-se no lado esquerdo da Tabela 1. O choque sobre esses produtos e com essas alíquotas apresentadas na tabela foi aplicado, 
de maneira uniforme, à demanda das famílias de todas as 27 regiões especificadas no modelo.

O procedimento utilizado para a implementação do Experimento 2 foi semelhante ao do Experimento 1. A diferença é que o usuário, no Experimento 2, é a Agropecuária, e não as famílias. Outra diferença é que os produtos objeto do choque passam a ser aqueles mais consumidos pela Agropecuária, dentre os 52 que compõem o banco de dados do modelo. Esses produtos são os quatro seguintes: Químicos Diversos, Outros Produtos Agropecuários, Outros Produtos Alimentares e Refino de Petróleo. Os valores calculados e utilizados para choque neste segundo experimento são mostrados no lado direito da Tabela 1. O choque para esses quatro produtos e com essas alíquotas foi aplicado, de maneira uniforme, à demanda da Agropecuária em todas as 27 regiões especificadas no modelo.

Tabela 1 - Valores dos choques adotados no Experimento 1 e no Experimento 2 - (em \%)

\begin{tabular}{|c|c|c|c|}
\hline \multicolumn{2}{|l|}{ Experimento 1} & \multicolumn{2}{|l|}{ Experimento 2} \\
\hline Produtos objeto do choque & Variação & Produtos objeto do choque & Variação \\
\hline $\begin{array}{l}\text { Outros Produtos } \\
\text { Agropecuários }\end{array}$ & $-3,0781 \%$ & Químicos Diversos & $-8,7595 \%$ \\
\hline Outros Produtos Alimentares & $-9,5469 \%$ & Outros Produtos Agropecuários & $-1,8109 \%$ \\
\hline Abate de Animais & $-4,9306 \%$ & Outros Produtos Alimentares & $-6,2906 \%$ \\
\hline $\begin{array}{l}\text { Beneficiamento de Produtos } \\
\text { Vegetais }\end{array}$ & $-8,8308 \%$ & Refino de Petróleo & $-3,9976 \%$ \\
\hline Indústria de Laticínios & $-7,9655 \%$ & & \\
\hline
\end{tabular}

Fonte: dados da pesquisa.

\section{Resultados e discussão}

Em razão do grande volume de informações produzidas por um modelo aplicado de equilíbrio geral com as características do TERM-BR, foi necessário adotar alguns critérios para facilitar a exposição. Primeiro, embora o modelo tenha sido implementado com o detalhamento de 27 regiões (26 estados e o Distrito Federal), optou-se por agregar os principais resultados regionais para o nível de 6 grandes regiões, a saber: Norte (N), Nordeste (NE), São Paulo (SP), Resto do Sudeste (RSE), Sul 
(S) e Centro-Oeste (CO). Segundo, privilegiou-se a exposição comparada dos resultados para as regiões Norte e Nordeste - que representam as regiões relativamente mais pobres do País - e São Paulo e Resto do Sudeste - representando as regiões mais ricas. Terceiro, embora o modelo permita investigar os impactos das mudanças na tributação indireta sobre uma grande quantidade de variáveis, limitou-se a análise a alguns indicadores econômicos considerados mais relevantes, dentre eles: PIB real e seus componentes, emprego, salário real, produção setorial e índice de preços ao consumidor por região e por classe de renda. Quarto, alguns resultados desagregados regional ou setorialmente, e mencionados no texto, são apresentados de modo mais detalhado em tabelas no Anexo. Quinto, ao invés da exposição detalhada dos valores encontrados para cada variável, procurou-se priorizar a exposição dos principais mecanismos causais subjacentes aos resultados, para isso, recorreu-se, nas explicações, a algumas informações - do banco de dados ou de resultados intermediários - que não aparecem nas tabelas apresentadas neste artigo, mas que podem ser obtidas contactando os autores por e-mail.

\subsection{Redução da tributação indireta sobre o consumo de alimentos (Experimento 1)}

Reduções nos tributos indiretos sobre alimentos são usualmente apontadas como exemplo de políticas que beneficiam a população de mais baixa renda. $\mathrm{O}$ argumento central é que medidas desse tipo - sob a hipótese de repasse, total ou parcial, das reduções nos tributos às famílias - reduzem os preços dos alimentos e, como esse tipo de despesa absorve parcela expressiva dos orçamentos da população de mais baixa renda, essas classes tenderiam a ser mais beneficiadas relativamente às de maior renda. Os demais efeitos de uma política como esta, especialmente seus efeitos setoriais e espaciais, são pouco explorados em estudos empíricos para o Brasil.

A Tabela 2 mostra os resultados de longo prazo do Experimento 1 para alguns dos principais agregados macroeconômicos para o Brasil e para seis grandes regiões (Norte, Nordeste, São Paulo, Resto do Sudeste, Sul e Centro-Oeste). Embora a discussão se inicie pelos resultados 
nacionais, deve-se salientar que o modelo, por ser do tipo bottom-up, é primeiramente resolvido para o nível das regiões, sendo o resultado nacional uma soma ponderada dos resultados regionais.

Tabela 2 - Efeitos de longo prazo do Experimento 1 sobre os principais agregados macroeconômicos - Brasil e grandes regiões - (em variação \%)

\begin{tabular}{l|c|c|c|c|c|c|c}
\hline & Brasil & N & NE & SP & RSE & S & CO \\
\hline Indicadores agregados & $-0,023$ & 0,432 & 0,196 & $-0,102$ & $-0,170$ & 0,141 & $-0,033$ \\
\hline PIB real & 1,293 & 1,293 & 1,293 & 1,293 & 1,293 & 1,293 & 1,293 \\
\hline Taxa de câmbio & \multicolumn{7}{|c}{} \\
\hline \multicolumn{10}{l}{} \\
\hline Demanda agregada & $-0,005$ & 0,728 & 0,324 & $-0,220$ & $-0,305$ & 0,217 & $-0,085$ \\
\hline Consumo real das famílias & $-0,130$ & 0,183 & 0,037 & $-0,178$ & $-0,269$ & 0,042 & $-0,102$ \\
\hline Investimento real & $-0,047$ & $-0,081$ & 0,065 & 0,008 & $-0,068$ & $-0,128$ & $-0,256$ \\
\hline Volume de exportação & $-0,033$ & 0,000 & $-0,126$ & $-0,171$ & 0,171 & $-0,054$ & $-0,033$ \\
\hline Volume de importação &
\end{tabular}

\begin{tabular}{l|c|c|c|c|c|c|c}
\hline Mercado de trabalho & \multicolumn{1}{l}{} \\
\hline Salário real médio & 1,257 & 1,644 & 1,450 & 1,188 & 1,127 & 1,405 & 1,226 \\
\hline Emprego & - & 0,386 & 0,193 & $-0,070$ & $-0,131$ & 0,148 & $-0,032$ \\
\hline
\end{tabular}

\begin{tabular}{|c|c|c|c|c|c|c|c|}
\hline \multicolumn{8}{|l|}{ Preços } \\
\hline \multicolumn{8}{|c|}{\begin{tabular}{l|l|l|l|l|l}
$-0,440$ & $-0,269$ & 0,088 & 0,167 & $-0,089$ & 0,357
\end{tabular}} \\
\hline Índice de preços das exportações & 1,305 & 1,313 & 1,277 & 1,291 & 1,310 & 1,325 & 1,357 \\
\hline Índice de preços das importações & 1,293 & 1,293 & 1,293 & 1,293 & 1,293 & 1,293 & 1,293 \\
\hline
\end{tabular}

Pode-se ver pela Tabela 2 que a redução dos tributos indiretos sobre os principais alimentos consumidos pelas famílias pouco afeta o PIB real brasileiro (redução de 0,023\%). Esse resultado está atrelado ao comportamento dos componentes do PIB real, que apresentam uma retração em decorrência da política; as exceções são o consumo do governo e as exportações líquidas (balança comercial) como proporção do PIB, que, por hipótese, são mantidos fixos no fechamento.

A redução do consumo real das famílias em nível nacional é uma decorrência da combinação dos efeitos diretos e indiretos da política sobre os diversos produtos especificados no modelo, do critério de pon- 
deração utilizado na obtenção dos resultados nacionais e, finalmente, das hipóteses adotadas no fechamento do modelo. Primeiramente, é importante ressaltar que o consumo real das famílias pelos cinco bens que foram alvo da redução de tributos aumentou em todas as regiões, elevando-se também em nível nacional. Houve também redução, por parte das famílias, no consumo real dos demais bens que não foram objeto da redução tributária. ${ }^{11}$ Essa redução no consumo desses produtos deve-se ao aumento nos seus preços, os quais, por sua vez, decorrem do aumento nos custos de produção em todas as atividades, como resultado indireto da política tributária. ${ }^{12}$

A variação apresentada na taxa de câmbio também está associada ao comportamento do consumo real das famílias e à hipótese adotada sobre a balança de comércio no fechamento. A redução nos tributos indiretos sobre os principais alimentos consumidos pelas famílias tem como efeito direto a redução nos preços desses mesmos produtos e o conseqüente aumento no seu consumo real por parte das famílias. Esse aumento no consumo desses cinco alimentos objeto da política absorve parte da produção doméstica que seria destinada às exportações, induzindo a balança comercial a um déficit. Para impedir esse déficit é necessário que haja um aumento nas exportações de outros produtos. Para que isso ocorra, é exigido que haja uma desvalorização da moeda nacional (aumento da taxa de câmbio R \$/US\$), de algo em torno de 1,293\%. Esta desvalorização eleva o índice de preços das importações em igual magnitude e eleva, em maiores proporções o índice de preços dos produtos exportados, em decorrência da escassez relativa de produtos para exportação. Este comportamento da taxa de câmbio é o principal elemento responsável pelo ajustamento na balança comercial em resposta à política tributária simulada no Experimento 1.

${ }^{11}$ A rigor, isso não ocorreu para todos os demais 47 produtos. Alguns poucos não apresentaram variação no consumo, mas são produtos tipicamente não consumidos diretamente pelas famílias - ao menos em volumes representativos - como Café em Coco e Cana-de-açúcar.

${ }^{12}$ Esses aumentos nos custos de produção são conseqüência do aumento dos preços dos diversos insumos intermediários e fatores de produção (trabalho, capital, e terra no caso da Agropecuária) e da desvalorização cambial ocorrida em resposta, que também afeta os preços e custos.

RER, Rio de Janeiro, vol. 45, no 04, p. 921-962, out/dez 2007 - Impressa em novembro 2007 
O emprego agregado, em nível nacional, por hipótese não se altera no longo prazo, mas varia setorialmente, sendo os maiores aumentos identificados nos setores denominados Outros Produtos Alimentares $(1,713 \%)$, Indústria de Laticínios $(1,505 \%)$, Beneficiamento de Produtos Vegetais $(0,721 \%)$, Agropecuária $(0,706 \%)$ e Abate de Animais $(0,636 \%)$. Embora o emprego em nível nacional não se altere, o salário real médio nacional aumenta de 1,257\%. Esse comportamento decorre do aumento do salário real médio em todas as seis grandes regiões, o que é conseqüência da mobilidade inter-regional da mão-de-obra.

Além dos resultados nacionais e do comportamento regional do salário real médio, a Tabela 2 mostra alguns dos principais efeitos regionais - para o nível de seis grandes regiões - da redução dos tributos sobre o consumo de alimentos pelas famílias. Nota-se que o resultado sobre o PIB das grandes regiões é heterogêneo; porém, é possível observar que ele cresce na região Sul e, especialmente, nas regiões mais pobres do País: Norte e Nordeste. Esse crescimento do PIB real de maneira mais acentuada nas regiões mais pobres deve-se principalmente à própria composição da estrutura produtiva dessas economias na situação anterior ao choque e ao aumento do consumo real das famílias após o choque, em particular dos produtos que foram objeto da redução tributária. Por outro lado, as regiões denominadas por São Paulo e Resto do Sudeste são as que acusam maior redução do consumo real das famílias e do PIB real. Esse comportamento do consumo real das famílias nessas duas regiões se deve ao fato de o peso dos produtos importados na pauta de consumo das famílias aí residentes ser superior ao das famílias de outras regiões do País, conforme revela o banco de dados do modelo. Assim, quando ocorre a desvalorização cambial em resposta à política tributária, os preços dos importados em moeda doméstica aumenta e compromete proporcionalmente mais o crescimento do consumo dessas famílias do que daquelas residentes em outras regiões do País. A própria estrutura de custos nessas regiões também sofre elevação em função do aumento dos preços dos importados.

A Tabela A.1, em anexo, detalha os resultados regionais sobre o comportamento do PIB real para as 27 regiões (estados) especificadas no modelo. Convém observar que há predominância de crescimento do PIB para os estados, como resposta à política simulada no Experimento 
1, as exceções são o Rio de Janeiro, São Paulo, Espírito Santo, além do Distrito Federal, pelas razões apontadas no parágrafo anterior.

Os resultados da Tabela 2 para as seis grandes regiões apontam crescimento do emprego naquelas onde ocorre aumento no PIB real: Norte, Nordeste e Sul. A expansão do nível de atividade econômica nessas regiões aumenta a demanda por trabalho - também por terra e capital - e o emprego; por conseguinte, o salário real aumenta nessas mesmas localidades. $\mathrm{O}$ crescimento no salário real nessas regiões atrai mão-de-obra de outras onde há retração no nível de atividade, provocando escassez relativa desse fator de produção nessas últimas localidades e uma conseqüente elevação dos salários reais médios. Estes movimentos no mercado de trabalho fazem com que, no longo prazo, os salários reais médios se aproximem em todas as regiões, mesmo nas que apresentam redução no PIB real e no emprego em resposta à política tributária em foco.

O índice de preços ao consumidor, em nível nacional, não se altera nas simulações apresentadas neste artigo, por hipótese de fechamento. No entanto, o Experimento 1 produz uma redução no índice de preços ao consumidor nas regiões mais pobres, Norte e Nordeste, e também na região Sul. Essa redução é fruto, em primeiro lugar, do maior peso relativo dos produtos alvo da política na pauta de consumo das famílias dessas três regiões, comparativamente ao peso desses produtos na cesta de consumo das famílias das demais regiões; assim, a redução nos preços dos produtos alvo da política em resposta ao choque beneficia mais as famílias residentes no Norte, Nordeste e no Sul do que às localizadas nas demais regiões. Outro elemento explicativo da queda no índice de preços ao consumidor nas regiões Norte, Nordeste e Sul e do aumento nas demais regiões deriva da diferença na participação dos produtos nacionais e importados na composição da pauta de consumo das famílias nessas regiões. A elevação dos preços dos produtos importados em resposta à política tributária simulada tem maior impacto sobre os índices de preços ao consumidor em São Paulo e no Resto do Sudeste do que nas regiões Norte, Nordeste e Sul.

A Tabela A.2, em anexo, informa sobre os resultados setoriais do Experimento 1. Ela mostra, para o Brasil e para as seis grandes regiões, a variação do nível de atividade econômica nos 42 setores especificados

RER, Rio de Janeiro, vol. 45, no 04, p. 921-962, out/dez 2007 - Impressa em novembro 2007 
no modelo, como resposta à redução na tributação sobre o consumo de alimentos, empreendida nesta primeira simulação. Na terceira coluna da Tabela A.2 é possível identificar que os setores que registram maior expansão, em termos nacionais, são exatamente os que têm como produção principal algum dos cinco produtos alvo da redução tributária. A tabela permite observar ainda que os resultados regionais não diferem significativamente do nacional quanto aos setores que apresentam maior expansão no nível de atividade econômica como produto do choque.

A Tabela 3 sintetiza as informações apresentadas na Tabela A.2. Ela traz, para o Brasil e as seis grandes regiões, os cinco setores que apresentam as maiores variações percentuais no nível de atividade em resposta à redução nos tributos indiretos sobre os principais alimentos consumidos pelas famílias. Ela permite constatar, mais facilmente, que os setores com melhor desempenho diante da política tributária simulada, em termos regionais, são os mesmos que em nível nacional, embora o ordenamento varie de uma região para outra. A Tabela 3 permite verificar também que esses cinco setores com maior crescimento apresentam melhor desempenho nas regiões Norte e Nordeste do País. Isso ocorre porque os produtos que sofreram redução nos tributos no Experimento 1 têm maior peso relativo no consumo das famílias dessas regiões do que nas demais, logo, o consumo desses bens e, por conseguinte, a produção dos setores que os ofertam, crescem mais nessas duas regiões do que nas demais.

Tabela 3 - Setores que apresentam maior crescimento no nível de atividade como resultado do Experimento 1 - Brasil e grandes regiões - (em variação \%)

\begin{tabular}{lcrccccc}
\hline Setor de atividade & Brasil & $\mathrm{N}$ & $\mathrm{NE}$ & $\mathrm{SP}$ & $\mathrm{RSE}$ & $\mathrm{S}$ & $\mathrm{CO}$ \\
\hline Outros produtos alimentares & 1,700 & 2,341 & 2,214 & 1,527 & 1,551 & 1,734 & 1,362 \\
Indústria de laticínios & 1,503 & 2,160 & 2,211 & 1,365 & 1,429 & 1,609 & 1,380 \\
Beneficiamento de produtos vegetais & 0,687 & 0,759 & 0,866 & 0,685 & 0,670 & 0,693 & 0,451 \\
Abate de animais & 0,636 & 1,182 & 1,101 & 0,540 & 0,636 & 0,594 & 0,512 \\
Agropecuária & 0,554 & 0,848 & 0,781 & 0,480 & 0,499 & 0,537 & 0,432 \\
\hline
\end{tabular}

Fonte: resultados da pesquisa

Nota: N (Norte), NE (Nordeste), SP (São Paulo), RSE (Resto do Sudeste), S (Sul), CO (Centro-Oeste).

Os resultados apresentados a seguir servem como indicativo dos efeitos potenciais sobre o bem-estar de uma política de redução dos 
tributos sobre o consumo de alimentos pelas famílias. A expectativa em experimentos como esse, conforme comentado, é que as classes de menor renda sejam relativamente mais beneficiadas do que as de maior renda, pois passariam a ter acesso facilitado aos bens dessa categoria de consumo, os quais absorvem grande parcela dos seus orçamentos. As famílias de mais baixa renda tendem a se beneficiar de um efeitorenda positivo oriundo da redução tributária expresso no aumento do consumo dos alimentos objeto da política e, eventualmente, da expansão do consumo de outros bens, desde que os preços para as famílias reduzam como resultado da política tributária.

A Tabela 4 informa o comportamento dos preços, para as famílias, dos cinco produtos que sofreram redução dos tributos indiretos nessa primeira simulação, nas seis grandes regiões. Podem ser detectadas reduções nos preços de todos eles, com média de queda superior a $5 \%$ em todas as seis regiões. Outros Produtos Alimentares é o que apresenta a maior queda em todas elas, 8,204\%, em média. Esses resultados evidenciam que, dada a estrutura dos mercados representada pelas equações do modelo, a política tributária abordada no Experimento 1 tem o potencial de reduzir os preços dos alimentos que são objeto da política. É importante informar ao leitor que os preços dos outros 47 bens e serviços não representados na Tabela 4 registraram aumento de aproximadamente $1,288 \%$ em todas as regiões, percentual bem inferior à redução verificada nos preços dos cinco produtos que foram objeto do choque.

Tabela 4 - Variação nos preços, para as famílias, dos produtos que sofreram redução nos tributos indiretos no Experimento 1 - grandes regiões - (em \%)

\begin{tabular}{lccccccc}
\hline Produtos & $\mathrm{N}$ & $\mathrm{NE}$ & $\mathrm{SP}$ & $\mathrm{RSE}$ & $\mathrm{S}$ & $\mathrm{CO}$ & Média \\
\hline Outros produtos agropecuários & $-1,436$ & $-1,465$ & $-1,597$ & $-1,569$ & $-1,546$ & $-1,430$ & $-1,507$ \\
Beneficiamento de produtos vegetais & $-7,376$ & $-7,403$ & $-7,420$ & $-7,400$ & $-7,399$ & $-7,323$ & $-7,387$ \\
Abate de animais & $-3,449$ & $-3,466$ & $-3,478$ & $-3,459$ & $-3,452$ & $-3,384$ & $-3,448$ \\
Indústria de laticínios & $-6,193$ & $-6,240$ & $-6,196$ & $-6,183$ & $-6,202$ & $-6,136$ & $-6,192$ \\
Outros produtos alimentares & $-8,214$ & $-8,235$ & $-8,219$ & $-8,205$ & $-8,206$ & $-8,146$ & $-8,204$ \\
Média & $-5,334$ & $-5,362$ & $-5,382$ & $-5,363$ & $-5,361$ & $-5,284$ & \\
\hline
\end{tabular}

Fonte: resultados da pesquisa

Nota: N (Norte), NE (Nordeste), SP (São Paulo), RSE (Resto do Sudeste), S (Sul), CO (Centro-Oeste). 
A Tabela 5 apresenta as variações percentuais no consumo das famílias para os cinco produtos que sofreram redução nos tributos indiretos no Experimento 1, para as seis grandes regiões. Devido ao efeito da redução tributária sobre os preços dos alimentos, discutido acima, o consumo desses produtos é aumentado em todas as regiões.

Tabela 5 - Variação no consumo das famílias dos produtos que sofreram redução nos tributos indiretos no Experimento 1 - grandes regiões - (em \%)

\begin{tabular}{l|c|c|c|c|c|c}
\hline Setor de atividade & $\mathrm{N}$ & $\mathrm{NE}$ & $\mathrm{SP}$ & $\mathrm{RSE}$ & $\mathrm{S}$ & $\mathrm{CO}$ \\
\hline Outros produtos agropecuários & 1,176 & 1,095 & 0,710 & 0,712 & 0,971 & 0,964 \\
Beneficiamento de produtos vegetais & 0,779 & 0,764 & 0,623 & 0,632 & 0,695 & 0,691 \\
Abate de animais & 1,245 & 1,191 & 0,875 & 0,873 & 1,056 & 1,055 \\
Indústria de laticínios & 2,083 & 2,033 & 1,632 & 1,63 & 1,854 & 1,827 \\
Outros produtos alimentares & 3,189 & 3,084 & 2,557 & 2,561 & 2,836 & 2,806 \\
\hline
\end{tabular}

Fonte: resultados da pesquisa

Nota: N (Norte), NE (Nordeste), SP (São Paulo), RSE (Resto do Sudeste), S (Sul), CO (Centro-Oeste).

A análise da variação no índice de preços por classes de renda reforça o potencial distributivo de uma política de redução nos tributos sobre o consumo de alimentos. A Tabela 6 mostra os resultados sobre a variação nos índices de preços ao consumidor no Brasil e nas seis grandes regiões para as 10 classes de renda definidas com base na Pesquisa de Orçamentos Famílias (POF).

Tabela 6 - Índices de preços ao consumidor por classe de renda como resultado do Experimento 1 - Brasil e grandes regiões - (em variação \%)

\begin{tabular}{l|c|c|r|r|r|r|r}
\hline & Brasil & N & NE & SP & RSE & S & CO \\
\hline POF[1] & $-1,079$ & $-1,537$ & $-1,200$ & $-1,010$ & $-0,614$ & $-1,152$ & $-0,353$ \\
POF[2] & $-0,895$ & $-1,227$ & $-1,049$ & $-0,833$ & $-0,753$ & $-0,833$ & $-0,328$ \\
POF[3] & $-0,668$ & $-0,970$ & $-0,967$ & $-0,551$ & $-0,486$ & $-0,443$ & $-0,207$ \\
POF[4] & $-0,431$ & $-0,996$ & $-0,721$ & $-0,035$ & $-0,308$ & $-0,539$ & $-0,092$ \\
POF[5] & $-0,359$ & $-0,908$ & $-0,676$ & $-0,207$ & $-0,210$ & $-0,284$ & $-0,012$ \\
POF[6] & $-0,233$ & $-0,984$ & $-0,567$ & 0,116 & $-0,199$ & $-0,188$ & $-0,190$ \\
POF[7] & $-0,036$ & $-0,577$ & $-0,410$ & 0,114 & 0,016 & 0,053 & 0,064 \\
POF[8] & 0,215 & $-0,029$ & $-0,079$ & 0,393 & 0,186 & 0,102 & 0,542 \\
POF[9] & 0,169 & $-0,176$ & 0,018 & 0,266 & 0,085 & 0,173 & 0,423 \\
POF[10] & 0,483 & 0,265 & 0,220 & 0,518 & 0,563 & 0,438 & 0,630 \\
\hline
\end{tabular}

Fonte: resultados da pesquisa

Nota: N (Norte), NE (Nordeste), SP (São Paulo), RSE (Resto do Sudeste), S (Sul), CO (Centro-Oeste). 
Os valores mostrados na Tabela 6 revelam que, de maneira geral, os preços tendem a cair relativamente mais para as classes de renda mais baixas em resposta ao choque implementado no Experimento 1. A divergência em termos desse padrão de comportamento, em nível de Brasil, ocorre apenas para a classe POF[9]. Para as três classes de maior renda, POF[8] a POF[10], os resultados para o Brasil mostram elevação dos índices de preços, o que indica que estas classes seriam penalizadas em termos absolutos com a política. A explicação para isto encontrase no fato dos produtos alvo da redução tributária possuírem pequena participação nas cestas de consumo das famílias de maior renda e pelo fato dos produtos importados - que tiveram seus preços elevados em decorrência política - terem maior peso nas cestas dessas famílias comparativamente às de renda mais baixa. Em termos regionais, as variações nos índices de preços ao consumidor por classe de renda, apresentadas na Tabela 6, sugerem que as populações de mais baixa renda localizadas nas regiões mais pobres do País - Norte e Nordeste - seriam as mais beneficiadas com a política de redução na tributação indireta sobre alimentos.

Um último aspecto relacionado a esta primeira simulação a ser analisado é o efeito da política sobre a arrecadação do governo. Embora esta versão do TERM-BR não permita uma análise detalhada do impacto sobre o resultado fiscal dos governos regionais e federal - por não modelar de forma completa as receitas e despesas desses governos - é possível verificar os impactos da política em questão sobre a arrecadação total de tributos indiretos, em nível nacional e regional. ${ }^{13}$ Os cálculos realizados com base nos resultados desta simulação apontam uma queda não trivial no total arrecadado de tributos indiretos. Em nível nacional, a redução na receita com esses tributos atinge 3,449\% quando se compara o total de receita após o choque com o da situação inicial. Em termos regionais, essa queda de receita é de 8,319\% no Norte, 6,940\% no Nordeste, 2,096\% em São Paulo, 3,210\% no Resto do Sudeste, $3,217 \%$ no Sul e 3,135\% no Centro-Oeste. Portanto, apesar do efeito

${ }^{13}$ Esta versão do TERM-BR não contém informações sobre a receita do governo oriunda da tributação direta. Uma versão ampliada deste modelo, com a inclusão de informações mais detalhadas sobre as diversas receitas e despesas do governo, está em desenvolvimento.

RER, Rio de Janeiro, vol. 45, no 04, p. 921-962, out/dez 2007 - Impressa em novembro 2007 
benéfico da mudança na tributação sobre o bem-estar da população de mais baixa renda, o impacto sobre a arrecadação é um fator que pode reduzir a sua viabilidade prática. Os resultados do Experimento 1 sobre a arrecadação de tributos indiretos para as 27 regiões especificadas no modelo são apresentados na Tabela A.3, em anexo.

\subsection{Redução da tributação indireta sobre insumos Agropecuários (Experimento 2)}

A segunda simulação (Experimento 2) explora os efeitos potenciais no longo prazo da redução de tributos indiretos sobre os principais insumos empregados na Agropecuária. A Tabela 7 sintetiza os principais resultados desta simulação sobre alguns agregados macroeconômicos no longo prazo para o Brasil e as seis grandes regiões. Ela mostra que a redução dos tributos indiretos sobre os principais insumos empregados na Agropecuária, de maneira uniforme para todas as regiões, tende a elevar o PIB real brasileiro de 0,050\%. Esse resultado decorre do aumento do consumo real das famílias e do investimento real em resposta à política.

O aumento no consumo real das famílias em nível nacional é resultado da combinação dos efeitos diretos e indiretos da política sobre os diversos produtos especificados no modelo, do critério de ponderação utilizado na obtenção dos resultados nacionais e, finalmente, das hipóteses adotadas no fechamento macroeconômico. A redução dos tributos indiretos sobre os principais insumos utilizados na Agropecuária, se repassada em algum grau aos preços, reduz os custos na Agropecuária e, por sua vez, reduz os preços dos bens intermediários e finais produzidos por esse setor. Como os produtos agropecuários constituem importantes insumos na produção de uma grande quantidade de produtos consumidos pelas famílias, a política em questão tem o potencial de, em certa medida, propagar a redução de preços para outros setores da economia, inclusive para aqueles menos dependentes dos insumos agropecuários. Reduções generalizadas nos preços dos bens e serviços podem levar, por sua vez, à expansão do consumo real das famílias. O efeito final deste Experimento 2 sobre o consumo real das famílias, apresentado na Tabela 7, reflete esta trajetória. 
Tabela 7 - Efeitos de longo prazo do Experimento 2 sobre os principais agregados macroeconômicos - Brasil e grandes regiões - (em variação \%)

\begin{tabular}{l|r|r|r|r|r|r|r}
\hline & Brasil & $\mathrm{N}$ & $\mathrm{NE}$ & $\mathrm{SP}$ & $\mathrm{RSE}$ & $\mathrm{S}$ & $\mathrm{CO}$ \\
\hline Indicadores agregados & & & & & & & \\
PIB real & 0,050 & 0,248 & 0,140 & $-0,014$ & $-0,028$ & 0,153 & 0,200 \\
Taxa de câmbio & 0,032 & 0,032 & 0,032 & 0,032 & 0,032 & 0,032 & 0,032 \\
& & & & & & & \\
Demanda agregada & & & & & & & \\
Consumo real das famílias & 0,055 & 0,345 & 0,183 & $-0,100$ & $-0,073$ & 0,185 & 0,254 \\
Investimento real & 0,045 & 0,194 & 0,145 & $-0,003$ & $-0,033$ & 0,151 & 0,214 \\
Volume de exportação & 0,081 & 0,088 & 0,282 & $-0,069$ & $-0,207$ & 0,412 & 0,831 \\
Volume de importação & 0,079 & 0,107 & 0,138 & $-0,027$ & 0,030 & 0,088 & 0,168 \\
& & & & & & & \\
Mercado de trabalho & & & & & & & \\
Salário real médio & 0,450 & 0,607 & 0,528 & 0,392 & 0,395 & 0,536 & 0,548 \\
Emprego & - & 0,157 & 0,077 & $-0,058$ & $-0,056$ & 0,086 & 0,098 \\
& & & & & & & \\
Preços & & & & & & & \\
Índice de preços ao consumidor & - & $-0,057$ & $-0,058$ & 0,010 & 0,014 & 0,017 & 0,076 \\
Índice de preços das exportações & 0,012 & 0,010 & $-0,038$ & 0,050 & 0,084 & $-0,071$ & \\
Índice de preços das importações & 0,032 & 0,032 & 0,032 & 0,032 & 0,032 & 0,032 & 0,032 \\
\hline
\end{tabular}

Fonte: resultados da pesquisa

Nota: N (Norte), NE (Nordeste), SP (São Paulo), RSE (Resto do Sudeste), S (Sul), CO (Centro-Oeste).

A variação na taxa de câmbio em resposta ao choque é uma decorrência do comportamento do consumo real das famílias e da hipótese adotada sobre a balança de comércio no fechamento. A redução nos tributos indiretos sobre os principais insumos utilizados na Agropecuária aumenta o consumo doméstico das famílias. Esse aumento de consumo absorve parte da produção doméstica que atenderia as exportações, induzindo a balança comercial a um déficit. Para impedir esse déficit é necessário que ocorra um aumento nas exportações de outros produtos, o que requer uma desvalorização da moeda nacional (aumento da taxa de câmbio R\$/US\$), no caso, da ordem de 0,032\%. Esta desvalorização eleva os preços das importações que, apesar disso, aumentam para atender parte do aumento do consumo doméstico. A desvalorização da moeda nacional mostra-se como o principal elemento de ajuste na balança comercial em resposta à política tributária simulada no Experimento 2. 
946 - Efeitos potenciais da política tributária sobre o consumo de alimentos e insumos agropecuários: uma análise de equilíbrio geral inter-regional

O emprego agregado, em nível nacional, por hipótese, não se altera no longo prazo, mas varia setorialmente. Os maiores aumentos no emprego se manifestam nos setores mais diretamente ligados à atividade agropecuária: Indústria do Açúcar (0,732\%), Indústria do Café $(0,650 \%)$, a própria Agropecuária $(0,644 \%)$, Abate de Animais $(0,557 \%)$ e Fabricação de Óleos Vegetais $(0,341 \%)$; esses são justamente os setores que apresentam maior crescimento.

A Tabela 7 fornece também os resultados dos principais impactos da política tributária do Experimento 2 sobre as seis grandes regiões. Nota-se que o PIB real aumenta na maioria delas, sendo exceções São Paulo e Resto do Sudeste. A redução do nível de atividade econômica nessas duas regiões decorre da retração no consumo real das famílias diante da política tributária simulada. A principal explicação para esse desempenho deve-se ao fato de o aumento nos preços dos produtos importados - devido à desvalorização cambial ocorrida em reação ao choque - exercer maior impacto sobre o consumo das famílias dessas duas regiões do que a redução ocorrida nos preços dos produtos mais fortemente ligados à Agropecuária e que foram objeto do choque.

A Tabela A.4, em anexo, exibe os resultados sobre o comportamento do PIB real para as 27 regiões (estados) especificadas no modelo, em resposta ao Experimento 2. Nela pode-se observar que a queda no PIB real manifesta-se apenas no Rio de Janeiro, Distrito Federal e São Paulo.

O comportamento do emprego e do salário real regionais está atrelado ao desempenho dos PIBs regionais. A política analisada, ao provocar uma expansão da atividade Agropecuária e de setores mais diretamente ligados a ela, aumenta a demanda de trabalho e o emprego nas regiões menos industrializadas e, portanto, mais dependentes do desempenho desses setores mais tradicionais. Dada a hipótese de emprego fixo em nível nacional e de mobilidade inter-regional da mão-de-obra, regiões mais industrializadas e de economia mais diversificada como São Paulo e Resto do Sudeste apresentam redução no emprego por cederem mão-de-obra para abastecer a expansão da atividade Agropecuária nas outras regiões. O resultado desse movimento no mercado de trabalho é o aumento do salário real em todas as regiões - inclusive em São Paulo e no Resto do Sudeste devido à escassez relativa de mão-de-obra que passa a existir - mas especialmente naquelas onde há aumento no emprego e no PIB real.

RER, Rio de Janeiro, vol. 45, no 04, p. 921-962, out/dez 2007 - Impressa em novembro 2007 
O índice de preços ao consumidor, em nível nacional, não se altera, por hipótese adotada no fechamento utilizado. Não obstante, o Experimento 2 provoca uma redução nos índices de preços ao consumidor nas regiões Norte e Nordeste. Esta redução é atribuída ao maior peso relativo dos produtos derivados da Agropecuária na pauta de consumo das famílias dessas regiões, comparativamente ao que se observa nas demais regiões.

A Tabela A.5, em anexo, fornece detalhes sobre os resultados setoriais do Experimento 2. Ela mostra a variação do nível de atividade econômica nos 42 setores especificados no modelo, no Brasil e nas seis grandes regiões. A partir dela é possível identificar que os setores que apresentam maior crescimento no nível de atividade, em termos nacionais, em decorrência do Experimento 2, são justamente aqueles mais diretamente ligados à atividade Agropecuária. Esses são também os setores que apresentam maior crescimento no emprego como fruto da política.

A Tabela 8 condensa as informações apresentadas na Tabela A.5 trazendo, para o Brasil e as seis grandes regiões, os cinco setores que apresentam as maiores variações percentuais no nível de atividade em resposta à redução nos tributos indiretos sobre os principais insumos empregados na Agropecuária. Esses setores são os mesmos tanto para o Brasil quanto para as seis grandes regiões, embora a ordenação varie de região para região.

Tabela 8 - Setores que apresentam maior crescimento no nível de atividade como resultado do Experimento 2 - Brasil e grandes regiões - (em variação \%)

\begin{tabular}{|c|c|c|c|c|c|c|c|}
\hline Setor de atividade & Brasil & $\mathrm{N}$ & $\mathrm{NE}$ & $\mathrm{SP}$ & RSE & $S$ & $\mathrm{CO}$ \\
\hline Indústria do café & 0,873 & 0,633 & 0,839 & 0,934 & 0,813 & 0,917 & 0,539 \\
\hline Indústria do açúcar & 0,849 & 0,368 & 0,845 & 0,926 & 0,571 & 0,694 & 0,761 \\
\hline Agropecuária & 0,722 & 0,802 & 0,743 & 0,674 & 0,705 & 0,765 & 0,677 \\
\hline Abate de animais & 0,679 & 0,583 & 0,520 & 0,602 & 0,569 & 0,786 & 0,650 \\
\hline Fabricação de óleos vegetais ${ }^{1}$ & 0,581 & 0,657 & 0,552 & 0,702 & 0,331 & 0,437 & 0,414 \\
\hline
\end{tabular}

Fonte: resultados da pesquisa (dados da Tabela A.5)

Nota: N (Norte), NE (Nordeste), SP (São Paulo), RSE (Resto do Sudeste), S (Sul), CO (Centro-Oeste).

${ }^{1}$ Para a região Sul (S), Fabricação de óleos vegetais, na verdade, é, na ordem, o sexto setor que apresenta maior crescimento em resposta ao choque do Experimento 2; o quinto é Beneficiamento de produtos vegetais.

RER, Rio de Janeiro, vol. 45, no 04, p. 921-962, out/dez 2007 - Impressa em novembro 2007 
Embora os resultados regionais apresentados na Tabela 8 praticamente não divirjam em termos dos setores que mais tendem a crescer diante da redução de tributos implementada no Experimento 2, em termos de magnitude as diferenças são mais expressivas em alguns casos. A Indústria do Açúcar, por exemplo, apresenta variações percentuais que vão desde 0,368\% na região Norte, a 0,926\% em São Paulo. Devese ressaltar, no entanto, com base nos dados básicos utilizados nesta pesquisa, que estado de São Paulo responde por $57,70 \%$ da produção nacional desta indústria, enquanto a região Norte como um todo participa com 0,25\%. Nota-se também que a Agropecuária, embora não seja o setor que apresenta o maior crescimento no Brasil em resposta ao choque implementado no Experimento 2, é o que exibe as menores discrepâncias de desempenho entre as regiões retratadas, variando entre $0,674 \%$ em São Paulo a $0,802 \%$ na região Norte.

A Tabela 9 exibe informações sobre a variação nos preços, para as famílias, dos cinco principais produtos alimentícios por elas consumidos, em resposta à redução dos tributos indiretos sobre insumos utilizados pela Agropecuária. Os resultados são apresentados para as seis grandes regiões. São detectadas reduções nos preços de todos eles, com média entre $0,6 \%$ e $0,7 \%$, aproximadamente, em todas as seis regiões. A maior queda, em todas as regiões, é para Outros Produtos Agropecuários, 1,218\%, em média. Todos os demais produtos, menos diretamente relacionados aos insumos da Agropecuária que foram alvo da redução tributária, apresentam elevação de preços, em média, de $0,2 \%$, após a simulação.

Tabela 9 - Variação nos preços, para as famílias, dos principais produtos alimentícios por elas consumidos, em resposta ao Experimento 2

- grandes regiões - (em \%)

\begin{tabular}{l|c|c|c|c|c|c|c}
\hline Produtos & $\mathrm{N}$ & $\mathrm{NE}$ & $\mathrm{SP}$ & $\mathrm{RSE}$ & $\mathrm{S}$ & $\mathrm{CO}$ & Média \\
\hline Outros produtos agropecuários & $-1,118$ & $-1,134$ & $-1,301$ & $-1,249$ & $-1,269$ & $-1,237$ & $-1,218$ \\
Beneficiamento de produtos vegetais & $-0,464$ & $-0,474$ & $-0,533$ & $-0,504$ & $-0,506$ & $-0,461$ & $-0,490$ \\
Abate de animais & $-0,646$ & $-0,662$ & $-0,726$ & $-0,698$ & $-0,729$ & $-0,660$ & $-0,687$ \\
Indústria de laticínios & $-0,754$ & $-0,759$ & $-0,823$ & $-0,798$ & $-0,778$ & $-0,745$ & $-0,776$ \\
Outros produtos alimentares & $-0,087$ & $-0,103$ & $-0,119$ & $-0,107$ & $-0,074$ & $-0,048$ & $-0,090$ \\
\hline Média & $-0,614$ & $-0,626$ & $-0,700$ & $-0,671$ & $-0,671$ & $-0,630$ & \\
\hline
\end{tabular}

Fonte: resultados da pesquisa

Nota: N (Norte), NE (Nordeste), SP (São Paulo), RSE (Resto do Sudeste), S (Sul), CO (Centro-Oeste). 
A Tabela 10 subsidia a discussão dos potenciais impactos sobre o bem-estar da política de redução nos tributos indiretos sobre insumos da Agropecuária. A tabela exibe os resultados das variações nos índices de preços ao consumidor no Brasil e nas seis grandes regiões para 10 classes de renda definidas com base na POF. Os índices revelam aspectos difíceis de serem captados através de instrumentais de equilíbrio parcial. Os valores mostrados na segunda coluna da tabela, referentes a Brasil, indicam que os preços ao consumidor tendem a cair relativamente mais para as classes de renda mais baixas. A única reversão desse padrão de comportamento ocorre ao se saltar da classe POF[8] para POF[9]. Em síntese, esses resultados nacionais sugerem que a redução nos tributos indiretos sobre os principais insumos utilizados na Agropecuária beneficia relativamente mais as classes de menor renda do que as de maior renda. Os resultados regionais dos índices de preços por classe de renda, comparados entre si, trazem outra importante informação sobre um tipo de política como esta, ausente em estudos anteriores para o Brasil utilizando modelos aplicados de equilíbrio geral: uma política tributária de redução nos tributos indiretos sobre os principais insumos empregados na Agropecuária tende a beneficiar relativamente mais as famílias mais pobres localizadas nas regiões mais pobres do País: Norte e Nordeste.

Tabela 10 - Índices de preços ao consumidor por classe de renda como resultado do Experimento 2 - Brasil e grandes regiões - (em variação \%)

\begin{tabular}{l|r|r|r|r|r|r|r}
\cline { 2 - 8 } \multicolumn{1}{c|}{} & Brasil & \multicolumn{1}{c|}{ N } & \multicolumn{1}{c|}{ NE } & \multicolumn{1}{c|}{ SP } & \multicolumn{1}{c|}{ RSE } & \multicolumn{1}{c}{ S } & \multicolumn{1}{c}{ CO } \\
\hline POF[1] & $-0,160$ & $-0,209$ & $-0,174$ & $-0,150$ & $-0,114$ & $-0,177$ & $-0,036$ \\
POF[2] & $-0,132$ & $-0,159$ & $-0,148$ & $-0,119$ & $-0,137$ & $-0,127$ & $-0,026$ \\
POF[3] & $-0,100$ & $-0,121$ & $-0,139$ & $-0,092$ & $-0,092$ & $-0,056$ & $-0,014$ \\
POF[4] & $-0,063$ & $-0,126$ & $-0,099$ & $-0,014$ & $-0,062$ & $-0,073$ & 0,010 \\
POF[5] & $-0,055$ & $-0,115$ & $-0,095$ & $-0,043$ & $-0,053$ & $-0,030$ & 0,020 \\
POF[6] & $-0,033$ & $-0,123$ & $-0,074$ & 0,010 & $-0,046$ & $-0,017$ & $-0,003$ \\
POF[7] & $-0,003$ & $-0,060$ & $-0,052$ & 0,008 & $-0,014$ & 0,029 & 0,037 \\
POF[8] & 0,037 & 0,021 & $-0,002$ & 0,054 & 0,013 & 0,039 & 0,111 \\
POF[9] & 0,026 & 0,001 & 0,013 & 0,028 & $-0,004$ & 0,051 & 0,090 \\
POF[10] & 0,073 & 0,070 & 0,043 & 0,065 & 0,069 & 0,091 & 0,119 \\
\hline
\end{tabular}

Fonte: resultados da pesquisa

Nota: N (Norte), NE (Nordeste), SP (São Paulo), RSE (Resto do Sudeste), S (Sul), CO (Centro-Oeste). 
950 - Efeitos potenciais da política tributária sobre o consumo de alimentos e insumos agropecuários: uma análise de equilíbrio geral inter-regional

Uma última observação a ser feita sobre esta simulação refere-se ao efeito da política em questão sobre a arrecadação de tributos indiretos. Cálculos realizados a partir de resultados do Experimento 2 apontam que, em nível nacional, a redução na receita com tributos indiretos atinge $1,075 \%$ quando se compara o total de receita após o choque com a da situação inicial. Em termos das grandes regiões, essa queda de receita é de $1,762 \%$ no Norte, $1,005 \%$ no Nordeste, 0,959\% em São Paulo, 0,565\% no Resto do Sudeste, 1,751\% no Sul e 2,601\% no Centro-Oeste. Portanto, apesar do efeito benéfico da mudança na tributação, especialmente para a população de baixa renda, o impacto sobre a arrecadação pode ser um fator que venha a reduzir o interesse pela sua implementação. Os resultados desta simulação sobre a arrecadação de tributos indiretos para as 27 regiões são apresentados na Tabela A.6, em anexo.

\section{Conclusões}

O objetivo deste trabalho foi analisar os efeitos potenciais de longo prazo sobre a economia brasileira de duas políticas no campo da tributação indireta: a redução dos tributos sobre o consumo de alimentos pelas famílias e a redução dos tributos sobre os principais insumos empregados na atividade Agropecuária. A análise foi empreendida através de simulações com o uso de um modelo aplicado de equilíbrio geral inter-regional.

A simulação da redução dos tributos indiretos sobre o consumo de alimentos pelas famílias sinalizou um aumento no nível de atividade econômica, no emprego, no salário real e na absorção interna nas regiões mais pobres do País - Norte e Nordeste - e queda no índice de preços ao consumidor. Os índices de preços por classe de renda e por região revelaram que esta política tem o potencial de melhorar o bem-estar dos grupos de rendas mais baixas, especialmente nas regiões mais pobres. Por outro lado, o impacto negativo desta medida sobre a arrecadação de tributos indiretos reduz a viabilidade prática de sua implantação, tornando-a mais dependente do maior ou menor grau de aversão à desigualdade dos formuladores de política econômica.

Na simulação da redução dos tributos indiretos sobre os principais insumos empregados na Agropecuária os resultados regionais, em ter-

RER, Rio de Janeiro, vol. 45, no 04, p. 921-962, out/dez 2007 - Impressa em novembro 2007 
mos de direção dos impactos, mostraram-se, semelhantes aos encontrados no experimento de redução dos tributos sobre alimentos. As diferenças principais encontraram-se nas magnitudes dos impactos: a redução dos tributos sobre insumos agropecuários produz menor impacto sobre a economia do que a redução na tributação sobre alimentos. Outro aspecto importante, tanto do ponto de vista teórico quanto empírico, derivado desta simulação, está relacionado ao trade-off entre eficiência e eqüidade, freqüentemente presente no debate sobre políticas tributárias alternativas. Os resultados sugerem que uma política tributária como esta simulada no Experimento 2 pode, ao mesmo tempo, promover crescimento no nível de atividade econômica e melhoraria no bem-estar das classes de menor renda, especialmente nas regiões mais pobres do País. O impacto negativo sobre a arrecadação de tributos indiretos - embora bem inferior ao da redução dos tributos sobre alimentos - pode também inibir a implementação de uma política como esta.

A principal contribuição deste trabalho encontra-se na importância dos resultados para a melhor compreensão dos potenciais efeitos regionais das políticas tributárias no Brasil e para orientação na formulação de políticas públicas. Os resultados obtidos no presente trabalho deixam claro que os impactos das políticas tributárias diferem regionalmente, muitas vezes de maneira substancial e, portanto, não devem ser negligenciados. Embora venha crescendo a utilização de modelos aplicados de equilíbrio geral no Brasil nos últimos anos, ainda predomina o uso de modelos que tratam o País como uma única região - modelos nacionais, isto é, sem detalhamentos regionais. O presente trabalho permite concluir que os resultados obtidos com os modelos de equilíbrio geral nacionais podem esconder importantes detalhes, os quais podem ser decisivos na formulação das políticas tributárias.

Em termos de orientação para formulação de políticas, o estudo permite afirmar que reduções na tributação indireta sobre alimentos e insumos agropecuários não compromete - ao menos significativamente - o crescimento econômico, no agregado, e podem ter importantes efeitos de melhoraria do bem-estar das classes de menor renda. Assim, essas políticas, embora possam ter efeitos negativos em termos da arrecadação tributária, podem ser facilmente justificadas tendo em vista o elevado grau de desigualdade característico do Brasil. Apesar do tra-

RER, Rio de Janeiro, vol. 45, no 04, p. 921-962, out/dez 2007 - Impressa em novembro 2007 
952 - Efeitos potenciais da política tributária sobre o consumo de alimentos e insumos agropecuários: uma análise de equilíbrio geral inter-regional

balho não explorar a questão, existem formas alternativas de compensar a perda de receita com tributos indiretos proveniente das políticas simuladas; por exemplo, através do aumento nas alíquotas dos tributos diretos sobre as classes de maior renda, ou ainda, por meio da intensificação do combate à sonegação.

\section{Referências bibliográficas}

DOMINGUES, E.P.; HADDAD, E.A. Política tributária e re-localização. Revista de Brasileira de Economia, Rio de Janeiro, v. 57, n. 4, p. 849871, out./dez. 2003.

FERREIRA FILHO, J.B.S.; HORRIDGE, M. Economic integration, poverty and regional inequality in Brazil. Clayton: Centre of Policy Studies, 2004. 39 p. (General working paper, G-149).

FOCHEZATTO, A.; CARVALHO, V.R. Como fazer descrição e análise quantitativa de dados. In: BÊRNI, D. de A. Técnicas de pesquisa em economia. São Paulo: Saraiva, 2002. p. 212-233.

HERTEL, T.W.(ed). Global Trade Analysis: modeling and applications. Cambridge University Press, 1997. 403 p.

HOFFMANN, R. Elasticidades-renda das despesas com alimentos em regiões metropolitanas do Brasil em 1995-96. Informações Econômicas, São Paulo, v. 30, n. 2, p. 17-24, 2000.

HORRIDGE, M. ORANI-G: a generic single-country computable general equilibrium model. Melbourne: Monash University, Centre of Policy Studies, 2001. 95 p.

HORRIDGE, M.; MADDEN, J.; WITTWER, G. The impact of the 20022003 drougth on Australia. Journal of Policy Modeling, New York, v. 27, n. 3, p. 285-308, Apr. 2005.

INSTITUTO BRASILEIRO DE GEOGRAFIA E ESTATÍSTICA - IBGE. Contas regionais do Brasil: 2002. 2. ed. Rio de Janeiro, 2004a. http:// www.ibge.gov.br (18 jan. 2005).

INSTITUTO BRASILEIRO DE GEOGRAFIA E ESTATÍSTICA - IBGE. 
Estatísticas do cadastro central de empresas: 2001. Rio de Janeiro, 2003a. http://www.ibge.gov.br (8 dez. 2004).

INSTITUTO BRASILEIRO DE GEOGRAFIA E ESTATÍSTICA - IBGE. Finanças públicas do Brasil: 2001-2002. Rio de Janeiro, 2004b. http:// www.ibge.gov.br (9 jan. 2005).

INSTITUTO BRASILEIRO DE GEOGRAFIA E ESTATÍSTICA - IBGE. Matriz de insumo-produto: Brasil: 1996. Rio de Janeiro: IBGE, 1999. http://www.ibge.gov.br (8 out. 2004).

INSTITUTO BRASILEIRO DE GEOGRAFIA E ESTATÍSTICA - IBGE. Pesquisa de orçamentos familiares 1995-1996: consumo alimentar domiciliar per capita. Rio de Janeiro: IBGE, 1998. 1 CD-ROM.

INSTITUTO BRASILEIRO DE GEOGRAFIA E ESTATÍSTICA - IBGE. Sistema de contas nacionais: Brasil 2000-2002. Rio de Janeiro, 2003b. v.10. http://www.ibge.gov.br (14 out. 2004).

INSTITUTO BRASILEIRO DE GEOGRAFIA E ESTATÍSTICA - IBGE. Sistema IBGE de recuperação automática - SIDRA. http://www.ibge. gov.br (15 maio 2005).

KEHOE, T.J.; NOYOLA, P.J.; MANRESA, A.; POLO, C.; SANCHO, F. A general equilibrium analysis of the 1986 tax reform in Spain. European Economic Review, Amsterdam, v. 32, n. 2-3, p. 334-342, Mar. 1988.

MAGALHÃES, L.C.G. de; SILVEIRA, F.G.; TOMICH, F.A.; VIANNA, S.W. Tributação, distribuição de renda e pobreza: uma análise dos impactos da carga tributária sobre alimentação nas grandes regiões urbanas brasileiras. Brasília: Instituto de Pesquisa Econômica Aplicada, 2001. 26 p. (IPEA. Texto para Discussão, 804).

MILLER, R.E.; BLAIR, P.D. Input-output analysis: foundations and extensions. Englewood Cliffs: Prentice-Hall, 1985. 464 p.

PAMBUDI, D.D. Regional strategies to attract investment: using a computable general equilibrium model of Indonesia. 2005. 157 p. Thesis (Doctor of Philosophy) - Faculty of Business and Economics, Monash University, Melbourne, 2005.

SANTOS, C.V. dos. Políticas tributárias, nível de atividade econômica 
954 - Efeitos potenciais da política tributária sobre o consumo de alimentos e insumos agropecuários: uma análise de equilíbrio geral inter-regional

e bem-estar: lições de um modelo de equilíbrio geral inter-regional. 2006. 139 p. Tese (Doutorado em Economia Aplicada) - Escola Superior de Agricultura “Luiz de Queiroz”, Universidade de São Paulo, Piracicaba, 2006.

TOURINHO, O.A.F.; KUME, H.; PEDROSO, A.C. de S. Elasticidades de Armington para o Brasil - 1986-2002: novas estimativas. Rio de Janeiro: Instituto de Pesquisa Econômica Aplicada, 2003. 22 p. (IPEA. Texto para Discussão, 974).

VIANNA, S.W.; MAGALHÃES, L.C.G. de; SILVEIRA, F.G.; TOMICH, F.A. Carga tributária direta e indireta sobre as unidades familiares no Brasil: avaliação de sua incidência nas grandes regiões urbanas em 1996. Brasília: Instituto de Pesquisa Econômica Aplicada, 2000. 60 p. (IPEA. Texto para Discussão, 757).

Recebido em janeiro de 2006 e revisto em agosto de 2007. 


\section{Anexos}

Tabela A.1 - Efeitos de longo prazo do Experimento 1 sobre o PIB real nas 27 regiões (estados) - (em variação \%)

\begin{tabular}{l|l|r}
\hline & Região & Variação \% \\
\hline 1 & Rondônia & 0,314 \\
2 & Acre & 0,209 \\
3 & Amazonas & 0,396 \\
4 & Roraima & 0,208 \\
5 & Pará & 0,563 \\
6 & Amapá & 0,454 \\
7 & Tocantins & 0,206 \\
8 & Maranhão & 0,499 \\
9 & Piauí & 0,386 \\
10 & Ceará & 0,162 \\
11 & Rio Grande do Norte & 0,193 \\
12 & Paraíba & 0,259 \\
13 & Pernambuco & 0,203 \\
14 & Alagoas & 0,294 \\
15 & Sergipe & 0,192 \\
16 & Bahia & 0,110 \\
17 & Minas Gerais & 0,047 \\
18 & Espírito Santo & $-0,137$ \\
19 & Rio de Janeiro & $-0,304$ \\
20 & São Paulo & $-0,102$ \\
21 & Paraná & 0,099 \\
22 & Santa Catarina & 0,090 \\
23 & Rio Grande do Sul & 0,205 \\
24 & Mato Grosso do Sul & 0,270 \\
25 & Mato Grosso & 0,304 \\
26 & Goiás & 0,005 \\
27 & Distrito Federal & $-0,333$ \\
\hline & & \\
\hline
\end{tabular}

Fonte: resultados da pesquisa 
956 - Efeitos potenciais da política tributária sobre o consumo de alimentos e insumos agropecuários: uma análise de equilíbrio geral inter-regional

Tabela A.2 - Efeitos de longo prazo do Experimento 1 sobre o nível de atividade setorial - Brasil e grandes regiões - (em variação \%)

\begin{tabular}{|c|c|c|c|c|c|c|c|c|}
\hline & Setor de atividade & Brasil & $\mathrm{N}$ & $\mathrm{NE}$ & SP & RSE & $S$ & $\mathrm{CO}$ \\
\hline 1 & Agropecuária & 0,554 & 0,848 & 0,781 & 0,480 & 0,499 & 0,537 & 0,432 \\
\hline 2 & Extrativa mineral & $-0,024$ & 0,146 & 0,136 & $-0,026$ & $-0,062$ & 0,110 & $-0,122$ \\
\hline 3 & Extração de petróleo e gás & 0,029 & 0,674 & 0,184 & $-0,018$ & $-0,033$ & 0,035 & 0,010 \\
\hline 4 & Minerais não-metálicos & $-0,098$ & 0,141 & 0,041 & $-0,132$ & $-0,192$ & 0,043 & $-0,239$ \\
\hline 5 & Siderurgia & $-0,105$ & 0,148 & 0,058 & $-0,115$ & $-0,137$ & $-0,006$ & $-0,275$ \\
\hline 6 & Metalurgia não-ferrosos & $-0,118$ & 0,038 & $-0,017$ & $-0,122$ & $-0,193$ & $-0,048$ & $-0,311$ \\
\hline 7 & Outros metalúrgicos & $-0,089$ & 0,297 & 0,168 & $-0,115$ & $-0,242$ & 0,048 & $-0,325$ \\
\hline 8 & Máquinas e tratores & $-0,058$ & 0,420 & 0,210 & $-0,104$ & $-0,188$ & 0,028 & $-0,258$ \\
\hline 9 & Material elétrico & $-0,219$ & 0,136 & $-0,065$ & $-0,230$ & $-0,439$ & $-0,085$ & $-0,363$ \\
\hline 10 & Equipamentos eletrônicos & $-0,230$ & 0,081 & $-0,145$ & $-0,247$ & $-0,500$ & $-0,116$ & $-0,489$ \\
\hline 11 & $\begin{array}{l}\text { Automóveis, caminhões e } \\
\text { ônibus }\end{array}$ & $-0,279$ & 0,363 & $-0,023$ & $-0,279$ & $-0,358$ & $-0,161$ & $-1,118$ \\
\hline 12 & Outros veículos e peças & $-0,130$ & 0,166 & 0,101 & $-0,134$ & $-0,262$ & $-0,068$ & $-0,484$ \\
\hline 13 & Madeira e mobiliário & $-0,263$ & 0,099 & $-0,035$ & $-0,333$ & $-0,433$ & $-0,228$ & $-0,361$ \\
\hline 14 & Papel e gráfica & $-0,019$ & 0,527 & 0,137 & $-0,030$ & $-0,201$ & 0,147 & $-0,318$ \\
\hline 15 & Indústria da borracha & $-0,141$ & 0,236 & 0,060 & $-0,153$ & $-0,280$ & 0,002 & $-0,135$ \\
\hline 16 & Elementos químicos & 0,054 & 0,577 & 0,235 & 0,009 & $-0,092$ & 0,184 & 0,051 \\
\hline 17 & Refino de petróleo & 0,034 & 0,682 & 0,173 & $-0,028$ & $-0,031$ & 0,222 & 0,029 \\
\hline 18 & Químicos diversos & 0,201 & 0,695 & 0,453 & 0,191 & 0,040 & 0,346 & 0,179 \\
\hline 19 & Farmacêutica e perfumaria & $-0,148$ & 0,265 & $-0,005$ & $-0,122$ & $-0,303$ & $-0,027$ & $-0,200$ \\
\hline 20 & Artigos de plástico & $-0,002$ & 0,356 & 0,236 & $-0,047$ & $-0,192$ & 0,128 & $-0,093$ \\
\hline 21 & Indústria têxtil & $-0,039$ & 0,496 & 0,177 & $-0,075$ & $-0,177$ & 0,022 & $-0,380$ \\
\hline 22 & Artigos do vestuário & $-0,205$ & 0,263 & 0,047 & $-0,294$ & $-0,382$ & $-0,077$ & $-0,335$ \\
\hline 23 & Fabricação de calçados & $-0,088$ & 0,181 & 0,094 & $-0,176$ & $-0,256$ & $-0,075$ & $-0,246$ \\
\hline 24 & Indústria do café & 0,152 & 0,224 & 0,291 & 0,150 & 0,099 & 0,149 & $-0,142$ \\
\hline 25 & $\begin{array}{l}\text { Beneficiamento de } \\
\text { produtos vegetais }\end{array}$ & 0,687 & 0,759 & 0,866 & 0,685 & 0,670 & 0,693 & 0,451 \\
\hline 26 & Abate de animais & 0,636 & 1,182 & 1,101 & 0,540 & 0,636 & 0,594 & 0,512 \\
\hline 27 & Indústria de laticínios & 1,503 & 2,160 & 2,211 & 1,365 & 1,429 & 1,609 & 1,380 \\
\hline 28 & Indústria de açúcar & 0,359 & 0,773 & 0,476 & 0,354 & 0,251 & 0,391 & 0,209 \\
\hline 29 & $\begin{array}{l}\text { Fabricação de óleos } \\
\text { vegetais }\end{array}$ & 0,316 & 0,548 & 0,471 & 0,265 & 0,243 & 0,429 & 0,142 \\
\hline 30 & $\begin{array}{l}\text { Outros produtos } \\
\text { alimentares }\end{array}$ & 1,700 & 2,341 & 2,214 & 1,527 & 1,551 & 1,734 & 1,362 \\
\hline 31 & Indústrias diversas & $-0,218$ & 0,343 & 0,091 & $-0,236$ & $-0,410$ & $-0,100$ & $-0,478$ \\
\hline 32 & $\begin{array}{l}\text { Serviços industriais de } \\
\text { utilidade pública }\end{array}$ & $-0,248$ & 0,372 & 0,080 & $-0,297$ & $-0,564$ & $-0,054$ & $-0,385$ \\
\hline
\end{tabular}


Cárliton Vieira dos Santos e Joaquim Bento de Souza Ferreira Filho • 957

\begin{tabular}{|c|c|c|c|c|c|c|c|c|}
\hline & Setor de atividade & Brasil & $\mathrm{N}$ & $\mathrm{NE}$ & SP & RSE & $\mathrm{S}$ & $\mathrm{CO}$ \\
\hline 33 & \begin{tabular}{|l} 
Construção civil \\
\end{tabular} & $-0,159$ & 0,021 & $-0,046$ & $-0,198$ & $-0,279$ & $-0,008$ & $-0,143$ \\
\hline 34 & Comércio & 0,043 & 0,621 & 0,344 & $-0,062$ & $-0,155$ & 0,238 & $-0,025$ \\
\hline 35 & Transportes & 009 & 0,432 & 0,196 & $-0,015$ & $-0,166$ & 0,224 & $-0,049$ \\
\hline 36 & Comunicações & $-0,285$ & 0,464 & $-0,007$ & $-0,380$ & $-0,421$ & $-0,034$ & $-0,298$ \\
\hline 37 & Instituições financeiras & $-0,143$ & 0,512 & 0,147 & $-0,141$ & $-0,365$ & 0,103 & $-0,309$ \\
\hline 38 & $\begin{array}{l}\text { Serviços prestados às } \\
\text { famílias }\end{array}$ & $-0,293$ & 0,278 & $-0,061$ & $-0,322$ & $-0,449$ & $-0,108$ & $-0,427$ \\
\hline 39 & $\begin{array}{l}\text { Serviços prestados às } \\
\text { empresas }\end{array}$ & $-0,037$ & 0,372 & 0,179 & $-0,041$ & $-0,154$ & 0,113 & $-0,264$ \\
\hline 40 & Aluguel de imóveis & $-0,270$ & 0,317 & $-0,063$ & $-0,276$ & $-0,440$ & $-0,072$ & $-0,321$ \\
\hline 41 & Administração pública & $-0,003$ & 0,020 & 0,010 & $-0,008$ & $-0,010$ & 0,008 & $-0,015$ \\
\hline 42 & $\begin{array}{l}\text { Serviços privados não- } \\
\text { mercantis }\end{array}$ & $-0,552$ & 0,486 & $-0,106$ & $-0,690$ & $-0,860$ & $-0,212$ & $-0,557$ \\
\hline
\end{tabular}

Fonte: resultados da pesquisa

Nota: N (Norte), NE (Nordeste), SP (São Paulo), RSE (Resto do Sudeste), S (Sul), CO (Centro-Oeste). 
958 - Efeitos potenciais da política tributária sobre o consumo de alimentos e insumos agropecuários: uma análise de equilíbrio geral inter-regional

Tabela A.3 - Efeitos de longo prazo do Experimento 1 sobre a arrecadação de tributos indiretos nas 27 regiões - (em variação \%)

\begin{tabular}{r|l|r}
\hline & Região & Variação \% \\
\hline 1 & Rondônia & $-7,699$ \\
2 & Acre & $-6,388$ \\
3 & Amazonas & $-7,164$ \\
4 & Roraima & $-9,465$ \\
5 & Pará & $-9,937$ \\
6 & Amapá & $-6,839$ \\
7 & Tocantins & $-5,392$ \\
8 & Maranhão & $-10,116$ \\
9 & Piauí & $-11,297$ \\
10 & Ceará & $-8,588$ \\
11 & Rio Grande do Norte & $-5,628$ \\
12 & Paraíba & $-8,177$ \\
13 & Pernambuco & $-6,317$ \\
14 & Alagoas & $-6,831$ \\
15 & Sergipe & $-7,159$ \\
16 & Bahia & $-5,392$ \\
17 & Minas Gerais & $-4,396$ \\
18 & Espírito Santo & $-3,582$ \\
19 & Rio de Janeiro & $-2,368$ \\
20 & São Paulo & $-2,096$ \\
21 & Paraná & $-3,248$ \\
22 & Santa Catarina & $-2,472$ \\
23 & Rio Grande do Sul & $-3,589$ \\
24 & Mato Grosso do Sul & $-4,723$ \\
25 & Mato Grosso & $-4,126$ \\
26 & Goiás & $-3,497$ \\
27 & Distrito Federal & $-1,708$ \\
\hline & a & \\
\hline
\end{tabular}

Fonte: resultados da pesquisa 
Tabela A.4 - Efeitos de longo prazo do Experimento 2 sobre o PIB real nas 27 regiões - (em variação \%)

\begin{tabular}{c|l|c}
\hline & Região & Variação \% \\
\hline 1 & Rondônia & 0,321 \\
2 & Acre & 0,321 \\
3 & Amazonas & 0,023 \\
4 & Roraima & 0,158 \\
5 & Pará & 0,325 \\
6 & Amapá & 0,268 \\
7 & Tocantins & 0,306 \\
8 & Maranhão & 0,392 \\
9 & Piauí & 0,216 \\
10 & Ceará & 0,015 \\
11 & Rio Grande do Norte & 0,057 \\
12 & Paraíba & 0,139 \\
13 & Pernambuco & 0,077 \\
14 & Alagoas & 0,324 \\
15 & Sergipe & 0,092 \\
16 & Bahia & 0,170 \\
17 & Minas Gerais & 0,107 \\
18 & Espírito Santo & 0,061 \\
19 & Rio de Janeiro & $-0,118$ \\
20 & São Paulo & $-0,014$ \\
21 & Paraná & 0,202 \\
22 & Santa Catarina & 0,170 \\
23 & Rio Grande do Sul & 0,102 \\
24 & Mato Grosso do Sul & 0,425 \\
26 & Mato Grosso & 0,482 \\
27 & Distrito Federal & 0,252 \\
& & $-0,057$ \\
\hline
\end{tabular}

Fonte: resultados da pesquisa 
960 - Efeitos potenciais da política tributária sobre o consumo de alimentos e insumos agropecuários: uma análise de equilíbrio geral inter-regional

Tabela A.5 - Efeitos de longo prazo do Experimento 2 sobre o nível de atividade setorial - Brasil e grandes regiões - (em variação \%)

\begin{tabular}{|c|c|c|c|c|c|c|c|c|}
\hline & Setor de atividade & Brasil & $\mathrm{N}$ & $\mathrm{NE}$ & $\mathrm{SP}$ & RSE & $S$ & $\mathrm{CO}$ \\
\hline 1 & gropecuária & 722 & 0,802 & 0,743 & 0,674 & 0,705 & 0,765 & 0,677 \\
\hline 2 & a mineral & 532 & $-0,698$ & $-0,363$ & $-0,245$ & $-0,597$ & $-0,280$ & $-0,394$ \\
\hline 3 & o de petróleo e gás & $-0,052$ & 0,278 & 0,009 & 0,003 & $-0,050$ & $-0,071$ & $-0,010$ \\
\hline 4 & não-metálicos & $-0,050$ & 0,058 & $-0,027$ & $-0,018$ & $-0,095$ & 0,011 & $-0,091$ \\
\hline 5 & yia & $-0,154$ & $-0,057$ & $-0,054$ & $-0,137$ & $-0,164$ & $-0,187$ & $-0,126$ \\
\hline 6 & Meta & $-0,255$ & $-0,335$ & $-0,243$ & $-0,240$ & $-0,276$ & $-0,225$ & $-0,261$ \\
\hline 7 & Outr & $-0,118$ & $-0,040$ & 0,028 & $-0,122$ & $-0,145$ & $-0,118$ & $-0,029$ \\
\hline 8 & ores & $-0,145$ & $-0,028$ & 0,038 & $-0,144$ & $-0,174$ & $-0,162$ & $-0,004$ \\
\hline 9 & 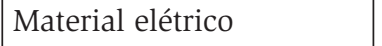 & $-0,106$ & $-0,016$ & 0,023 & $-0,129$ & $-0,145$ & $-0,024$ & 0,128 \\
\hline 10 & 200 & $-0,179$ & $-0,049$ & 0,038 & $-0,215$ & $-0,182$ & $-0,110$ & 0,102 \\
\hline 11 & $\begin{array}{l}\text { Automóveis, caminhões e } \\
\text { ônibus }\end{array}$ & -0 & 1 & $-c$ & -0 & $-0,166$ & $-0,103$ & $-0,270$ \\
\hline 12 & zeículos e necas & $-0,359$ & $-0,218$ & $-0,057$ & $-0,357$ & $-0,312$ & $-0,436$ & $-0,074$ \\
\hline 13 & $\mathrm{ad}$ & 0,114 & 0,244 & 0,253 & 0,072 & 0,065 & 0,117 & 0,194 \\
\hline 14 & $\mathrm{ca}$ & $-0,078$ & 0,110 & 0,019 & $-0,095$ & $-0,133$ & $-0,014$ & $-0,061$ \\
\hline 15 & 19а & $-0,071$ & 0,073 & $-0,004$ & $-0,064$ & $-0,123$ & $-0,082$ & 0,014 \\
\hline 16 & en & 0,267 & 0,354 & 0,347 & 0,249 & 0,179 & 0,304 & 0,321 \\
\hline 17 & & 0,025 & 0,313 & 0,077 & $-0,002$ & $-0,003$ & 0,111 & 0,262 \\
\hline 18 & $s$ & 0,271 & 0,343 & 0,349 & 0,266 & 0,168 & 0,394 & 0,446 \\
\hline 19 & Farm & 0 & 0 & 0 & 0 & -0 & 0,080 & 0,135 \\
\hline 20 & lástico & $-0,023$ & 117 & 0,065 & $-0,045$ & $-0,074$ &, 021 & 0,115 \\
\hline 21 & Ind $\mathrm{s}-\mathrm{e}$ & 0,217 & 0,235 & 0,247 & 0,238 & 0,127 & 0,193 & 0,088 \\
\hline 22 & 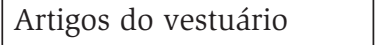 & 0,015 & 0,159 & 0,068 & $-0,019$ & $-0,041$ & 0,059 & 0,096 \\
\hline 23 & & & & $-0,174$ & $-0,203$ & $-0,187$ & $-0,302$ & $-0,092$ \\
\hline 24 & é & 0,873 & 0,6 & 0,839 & 0,934 & 0,813 & 0,917 & 0,539 \\
\hline 25 & Beneficiamento de & 0 & & 0 & 0,454 & 0,309 & 0,547 & 0,402 \\
\hline 26 & is & 579 & 0,583 & 0,520 & 0,602 & 0,569 & 0,786 & 0,650 \\
\hline 27 & dústria de laticínios & 0,325 & 0,366 & 0,265 & 0,315 & 0,322 & 0,367 & 0,353 \\
\hline 28 & ia de açúcar & 0,849 & 0,368 & 0,845 & 0,926 & 0,571 & 0,694 & 0,761 \\
\hline 29 & $\begin{array}{l}\text { Fabricação de óleos } \\
\text { vegetais }\end{array}$ & 581 & 0,657 & 0,552 & 0,702 & 0,331 & 0,437 & 0,414 \\
\hline 30 & $\begin{array}{l}\text { Outros produtos } \\
\text { alimentares }\end{array}$ & & & 0,228 & 0,164 & 0,1 & 0,251 & 0,269 \\
\hline 31 & Indústrias diversas & $-0,211$ & $-0,014$ & $-0,078$ & $-0,228$ & $-0,238$ & $-0,226$ & $-0,096$ \\
\hline
\end{tabular}

RER, Rio de Janeiro, vol. 45, no 04, p. 921-962, out/dez 2007 - Impressa em novembro 2007 
Cárliton Vieira dos Santos e Joaquim Bento de Souza Ferreira Filho 961

\begin{tabular}{|c|c|c|c|c|c|c|c|c|}
\hline & Setor de atividade & Brasil & $\mathrm{N}$ & $\mathrm{NE}$ & SP & RSE & $\mathrm{S}$ & $\mathrm{CO}$ \\
\hline 32 & $\begin{array}{l}\text { Serviços industriais de } \\
\text { utilidade pública }\end{array}$ & $-0,055$ & 0,146 & 0,090 & $-0,108$ & $-0,196$ & 0,037 & 0,011 \\
\hline 33 & Construção civil & 0,042 & 0,128 & 0,094 & 0,010 & $-0,028$ & 0,126 & 0,137 \\
\hline 34 & Comércio & 0,075 & 0,284 & 0,179 & $-0,003$ & $-0,017$ & 0,185 & 0,221 \\
\hline 35 & Transportes & $-0,062$ & 0,045 & 0,036 & $-0,088$ & $-0,162$ & 0,067 & 0,088 \\
\hline 36 & Comunicações & $-0,037$ & 0,307 & 0,099 & $-0,137$ & $-0,101$ & 0,111 & 0,160 \\
\hline 37 & Instituições financeiras & $-0,039$ & 0,214 & 0,087 & $-0,054$ & $-0,156$ & 0,101 & 0,087 \\
\hline 38 & $\begin{array}{l}\text { Serviços prestados às } \\
\text { famílias }\end{array}$ & $-0,031$ & 0,194 & 0,072 & $-0,070$ & $-0,089$ & 0,064 & 0,050 \\
\hline 39 & $\begin{array}{l}\text { Serviços prestados às } \\
\text { empresas }\end{array}$ & $-0,244$ & $-0,146$ & $-0,170$ & $-0,267$ & $-0,281$ & $-0,145$ & $-0,233$ \\
\hline 40 & Aluguel de imóveis & $-0,018$ & 0,226 & 0,052 & $-0,035$ & $-0,100$ & 0,101 & 0,102 \\
\hline 41 & Administração pública & $-0,010$ & $-0,006$ & $-0,006$ & $-0,014$ & $-0,010$ & $-0,007$ & $-0,008$ \\
\hline 42 & $\begin{array}{l}\text { Serviços privados não- } \\
\text { mercantis }\end{array}$ & $-0,191$ & 0,184 & $-0,035$ & $-0,306$ & $-0,313$ & $-0,024$ & 0,060 \\
\hline
\end{tabular}

Fonte: resultados da pesquisa

Nota: N (Norte), NE (Nordeste), SP (São Paulo), RSE (Resto do Sudeste), S (Sul), CO (Centro-Oeste). 

uma análise de equilíbrio geral inter-regional

Tabela A.6 - Efeitos de longo prazo do Experimento 2 sobre a arrecadação de tributos indiretos nas 27 regiões - (em variação \%)

\begin{tabular}{c|l|r}
\hline & Região & Variação \% \\
\hline 1 & Rondônia & $-2,726$ \\
2 & Acre & $-3,962$ \\
3 & Amazonas & $-0,484$ \\
4 & Roraima & $-1,511$ \\
5 & Pará & $-2,023$ \\
6 & Amapá & $-1,029$ \\
7 & Tocantins & $-2,355$ \\
8 & Maranhão & $-1,515$ \\
9 & Piauí & $-0,940$ \\
10 & Ceará & $-0,625$ \\
11 & Rio Grande do Norte & $-0,695$ \\
12 & Paraíba & $-1,458$ \\
13 & Pernambuco & $-0,680$ \\
14 & Alagoas & $-1,411$ \\
15 & Sergipe & $-0,298$ \\
16 & Bahia & $-1,272$ \\
17 & Minas Gerais & $-1,874$ \\
18 & Espírito Santo & $-1,984$ \\
19 & Rio de Janeiro & $-0,222$ \\
20 & São Paulo & $-0,563$ \\
21 & Paraná & $-2,041$ \\
22 & Santa Catarina & $-2,193$ \\
23 & Rio Grande do Sul & $-1,274$ \\
24 & Mato Grosso do Sul & $-4,830$ \\
25 & Mato Grosso & $-6,035$ \\
26 & Goiás & $-2,416$ \\
27 & Distrito Federal & $-0,271$ \\
\hline & & \\
\hline
\end{tabular}

Fonte: resultados da pesquisa. 